\title{
Leukocyte Common Antigen-Related Phosphatase Is a Functional Receptor for Chondroitin Sulfate Proteoglycan Axon Growth Inhibitors
}

\author{
Daniel Fisher, ${ }^{1}$ Bin Xing, ${ }^{1}$ John Dill, ${ }^{1}$ Hui Li, ${ }^{1}$ Hai Hiep Hoang, ${ }^{1}$ Zhenze Zhao, ${ }^{1}$ Xiao-Li Yang, ${ }^{1}$ Robert Bachoo, ${ }^{1}$ \\ Stephen Cannon, ${ }^{1}$ Frank M. Longo, ${ }^{2}$ Morgan Sheng, ${ }^{3}$ Jerry Silver, ${ }^{4}$ and Shuxin Li ${ }^{1}$ \\ ${ }^{1}$ Department of Neurology and Neuroscience Graduate Program, University of Texas Southwestern Medical Center, Dallas, Texas 75390-8813, ${ }^{2}$ Department \\ of Neurology and Neurological Science, Stanford University, Stanford, California 94305, ${ }^{3}$ The Picower Institute for Learning and Memory, \\ RIKEN-Massachusetts Institute of Technology Neuroscience Research Center, Howard Hughes Medical Institute, Massachusetts Institute of Technology, \\ Cambridge, Massachusetts 02139, and ${ }^{4}$ Department of Neurosciences, Case Western Reserve University, Cleveland, Ohio 44106
}

Chondroitin sulfate proteoglycans (CSPGs) are a family of extracellular matrix molecules with various functions in regulating tissue morphogenesis, cell division, and axon guidance. A number of CSPGs are highly upregulated by reactive glial scar tissues after injuries and form a strong barrier for axonal regeneration in the adult vertebrate CNS. Although CSPGs may negatively regulate axonal growth via binding and altering activity of other growth-regulating factors, the molecular mechanisms by which CSPGs restrict axonal elongation are not well understood. Here, we identified a novel receptor mechanism whereby CSPGs inhibit axonal growth via interactions with neuronal transmembrane leukocyte common antigen-related phosphatase (LAR). CSPGs bind LAR with high affinity in transfected COS-7 cells and coimmunoprecipitate with LAR expressed in various tissues including the brain and spinal cord. CSPG stimulation enhances activity of LAR phosphatase in vitro. Deletion of LAR in knock-out mice or blockade of LAR with sequence-selective peptides significantly overcomes neurite growth restrictions of CSPGs in neuronal cultures. Intracellularly, CSPG-LAR interaction mediates axonal growth inhibition of neurons partially via inactivating Akt and activating RhoA signals. Systemic treatments with LAR-targeting peptides in mice with thoracic spinal cord transection injuries induce significant axon growth of descending serotonergic fibers in the vicinity of the lesion and beyond in the caudal spinal cord and promote locomotor functional recovery. Identification of LAR as a novel CSPG functional receptor provides a therapeutic basis for enhancing axonal regeneration and functional recovery after CNS injuries in adult mammals.

\section{Introduction}

Following axonal injuries, chondroitin sulfate proteoglycans (CSPGs) generated by the reactive glial scar tissues significantly contribute to axon growth failure in the CNS (Snow et al., 1990; McKeon et al., 1991; Bradbury et al., 2002; Silver and Miller, 2004). The major CSPGs found in the CNS include neurocan, versican, aggrecan, brevican, phosphacans, and NG2. Structurally, CSPG molecules contain a single core protein and one or more polysaccharide glycosaminoglycan (GAG) chains. After CNS injuries, CSPGs are considerably upregulated in reactive astrocytes and oligodendrocyte progenitors and the increased CSPG concentrations form a potent chemical barrier for axonal regeneration by preventing elongation (Bradbury et al., 2002;

Received April 6, 2011; revised Aug. 8, 2011; accepted Aug. 10, 2011.

Author contributions: S.L., S.C., F.M.L., and J.S. designed research; S.L., D.F., B.X., J.D., H.L., H.H.H., Z.Z., X.-L.Y., and R.B. performed research; F.M.L. and M.S. contributed unpublished reagents/analytic tools; S.L. and D.F. analyzed data; S.L. and J.S. wrote the paper.

This work was supported by Paralyzed Veterans of America Grants 2584 and 2516, NIH Grant 1R21 NS06611401A1, the Morton Cure Paralysis Fund, and Christopher and Dana Reeve Foundation (S.L.), and NIH Grant NSO25713 (J.S.). We thank Ankur R. Patel, Brittany Mason, and Lin Cui for technical support.

Correspondence should be addressed to Shuxin Li, Department of Neurology, University of Texas Southwestern Medical Center at Dallas, 5323 Harry Hines Boulevard, Dallas, TX 75390-8813. E-mail: shuxin.li@utsouthwestern.edu.

DOI:10.1523/JNEUROSCI.1737-11.2011

Copyright $\odot 2011$ the authors $\quad 0270-6474 / 11 / 3114051-16 \$ 15.00 / 0$
Jones et al., 2003; Sherman and Back, 2008). The GAG chains of CSPGs play a critical role in regulating the suppression properties of CSPGs because removing chondroitin sulfate GAGs from the core protein attenuates CSPG inhibition and facilitates axonal regeneration. Particularly, enzymatic cleavage of GAG chains with bacterial chondroitinase $\mathrm{ABC}$ (ChABC) reduces CSPG suppression and enhances axonal regeneration of nigrostriatal, corticospinal, and ascending fibers, and improving functional recovery after CNS injuries (Moon et al., 2001; Bradbury et al., 2002; Cafferty et al., 2007; García-Alías et al., 2008; Tester and Howland, 2008; Jefferson et al., 2011). ChABC combined with cell transplants further promotes axonal regeneration after spinal cord injury (SCI) (Fouad et al., 2005; Houle et al., 2006; Kim et al., 2006; Tom et al., 2009; Alilain et al., 2011). Thus, CSPG axonal growth inhibitors are important targets for overcoming growth repression in the injured CNS.

The molecular mechanisms by which CSPGs restrict axonal growth are not well understood. The inhibitory actions of CSPGs are dependent on the sulfation pattern of GAG chains (Sherman and Back, 2008). CSPGs have been shown to suppress axonal growth via negatively charged sulfate (Gilbert et al., 2005) or via binding and blocking growth-promoting effects of some extracellular matrix molecules, such as laminin and tenascin (Sher- 
man and Back, 2008). CSPGs may also contribute to repressing properties of the inhibitory molecule semaphorin 5A by binding its thrombospondin domain via the GAG chains (Kantor et al., 2004). However, most axonal growth inhibitors in the CNS restrict axonal extension via binding their interacting receptor proteins on the membrane (Klein, 2004; Liu et al., 2006). It is very likely that CSPGs mediate neuronal growth suppression primarily through binding and activating functional receptors on the membrane. Most recently, two studies indicate that receptor protein tyrosine phosphatase $\sigma(\mathrm{RPTP} \sigma)$ acts as a receptor for CSPGs and partially mediates the ability of CSPGs to restrict regenerative neurite outgrowth (Shen et al., 2009; Fry et al., 2010). Here, we report that the transmembrane leukocyte common antigenrelated phosphatase (LAR) receptor, another member in the LAR subfamily of RPTPs, plays an important role in regulating inhibition of axonal elongation by functioning as a receptor for CSPG inhibitors. We demonstrate that CSPGs bind LAR phosphatase with high affinity and CSPG stimulation significantly enhances LAR activity in vitro. Functional blockade of LAR reverses neurite growth inhibition induced by CSPGs. Treatments with LARtargeting peptides induce significant descending axonal growth in the caudal spinal cord and promote locomotor functional recovery in rodents with SCI. Our study suggests that LAR phosphatase is a novel molecular target for promoting axonal regeneration and functional recovery in the injured CNS.

\section{Materials and Methods}

Sources of compounds. Antibodies against the following proteins were used: CSPG (clone Cat-316; 1:4000; Millipore), rabbit anti-LAR (the intracellular domain amino acids 1081-1150; 1:200 for immunostaining; Santa Cruz Biotechnology), goat anti-LAR [the C-terminal cytoplasmic domain of rat origin LAR for coimmunoprecipitation (co-IP); Santa Cruz Biotechnology], mouse anti-LAR (the N-terminal cytoplasmic domain of human origin LAR; 1:500 for Western blots; BD Biosciences Transduction Laboratories), versican (the amino acid residues 4364416 of human versican; 1:1000 for blotting; Sigma-Aldrich), rat neurocan (1:1000 for blotting; Sigma-Aldrich), c-myc (9E10; Santa Cruz), NeuN (1:500 for neuronal staining; Millipore), neurofilament (1:200; Sigma-Aldrich), neuron-specific class III $\beta$-tubulin (Tuj1; 1:500; Abcam), 5-HT (1:4000; ImmunoStar), Akt, Akt-p, collapsin response mediator protein-2 (CRMP2), CRMP2-p (1:1000; Cell Signaling Technology), and RhoA (1:1000; Santa Cruz Biotechnology). The major proteins used include the mixture of purified CSPGs containing neurocan, versican, phosphacan, and aggrecan (Millipore), purified chondroitin sulfate (400 $\mu \mathrm{g} / \mathrm{ml}$; Sigma-Aldrich), protease-free ChABC $(2 \mathrm{U} / \mathrm{ml}$; Sigma-Aldrich) (Qin et al., 2006), Rho binding domain (RBD) beads (Cytoskeleton), and laminin (Sigma-Aldrich). The random sequence peptide (RP), the extracellular LAR peptide (ELP) [described as L59 in the study by Yang et al. (2005)], and the intracellular LAR peptide (ILP) [described as WLAR in the study by Xie et al. (2006)] were synthesized by $\mathrm{CHI}$ Scientific, and their purity was analyzed via HPLC. The LAR mutation in the first Ig-like domain was generated by changing lysine residues K68, K69, K71, and K72 of human LAR to alanines with PCR. The other LAR plasmids were provided by $\mathrm{M}$. Sheng, including wild-type LAR (LAR-WT), LAR with the $\mathrm{D} 2$ domain deletion mutant $\Delta \mathrm{D} 2$, and LAR mutant $\mathrm{C} 1522 \mathrm{~S}$ containing a cysteine-to-serine missense mutation in the D1 domain (Dunah et al., 2005). The protein tyrosine phosphatase (PTP) activity in the lysates of transfected COS-7 cells was measured via a nonradioactive phosphotyrosine phosphatase assay using the PTP-101 kit (Sigma-Aldrich).

Immunohistochemistry and immunoprecipitation. To visualize cellular distribution of LAR in CNS tissues, we stained sections of fixed spinal cord and brain harvested from wild-type or LAR mutant mice after perfusion with $4 \%$ paraformaldehyde. The parasagittal spinal cord and coronal brain sections were incubated with a rabbit anti-LAR antibody. LAR protein was visualized via an Alexa 594 anti-rabbit secondary antibody.
To localize LAR signal to definite cells, cell type-specific antibodies (NeuN for neurons, neurofilament for axon cylinders, and 5-HT for serotonergic neuron/axons) were applied in some sections.

COS-7 cells were grown in DMEM supplemented with 10\% fetal bovine serum in $60 \mathrm{~mm}$ dishes and transfected with LAR-WT or LAR mutants. Two days after transfection, cells were prepared in $300 \mu$ l of cold lysis buffer supplemented with protease inhibitors ( $1 \mathrm{~mm}$ phenylmethylsulfonyl fluoride, $2 \mathrm{~mm}$ orthovanadate, $10 \mu \mathrm{g} / \mathrm{ml}$ leupeptin, and 10 $\mu \mathrm{g} / \mathrm{ml}$ aprotinin) and clarified by centrifugation at $15,000 \times g$ for $10 \mathrm{~min}$ at $4^{\circ} \mathrm{C}$. The tissue lysates were prepared from adult mice with spinal cord injury or from the age-matched normal mice. For the former, a dorsal hemitransection injury was performed at T7 level in female mice (8-10 weeks of age). Seven days after the injury, mice were perfused through heart with cold PBS for $5 \mathrm{~min}$, and the spinal cord containing injury site at T4-T10 was harvested immediately after perfusion. For the latter, age-matched adult female mice with sham surgery were perfused with PBS, and the spinal cord at T4-T10, brain, aorta, lung, and skeletal muscle were dissected out. All of these tissues were collected on dry ice immediately and stored at $-80^{\circ} \mathrm{C}$. Tissues were prepared in lysis buffer supplemented with protease inhibitors. Following sonification and centrifugation to remove tissue debris, total protein concentration in supernatants was determined with Bio-Rad DC protein assay reagents. Samples containing the same amount of protein in cell or tissue supernatants were used for Western blot and co-IP assays. For LAR expression in COS-7 cells or tissues, a rabbit antibody against the LAR intracellular domain amino acids 1081-1150 (Santa Cruz Biotechnology) or a purified mouse antibody against the $\mathrm{N}$-terminal sequence of human LAR was used. For versican protein determination in tissues, a rabbit antibody against amino acid residues 436-4416 of human versican was applied (Sigma-Aldrich).

In selected experiments, cell or tissue supernatants containing the same amount of protein were used for co-IP with Pierce protein G immunoprecipitation kit. After bead preparations following the manufacturer's instructions, a mouse monoclonal antibody against amino acids $408-439$ of c-myc (9E10; Santa Cruz) was coupled to beads to pull down LAR protein in COS-7 supernatants. The constructs of LAR-WT and LAR mutants were conjugated to c-myc (Dunah et al., 2005). A bait-prey protein complex in COS-7 cell supernatants was created by adding purified CSPGs to the supernatants at $5.2 \mu \mathrm{g} / \mathrm{ml}$ before incubating with antibody-coupled beads. For tissue supernatants, a goat antibody raised against the C-terminal cytoplasmic domain of rat origin LAR (Santa Cruz Biotechnology) was coupled to the beads. After $2 \mathrm{~h}$ incubation with various tissue supernatants, beads were washed with coupling buffer four times. After 5 min heating in $2 \times$ Laemmli buffer, the denatured samples were loaded to $4-20 \%$ gradient SDS-PAGE gels for Western blotting. The blots were probed with a mouse anti-neurocan (for COS-7 cell supernatants) or rabbit anti-versican (for tissue supernatants; SigmaAldrich) antibody. Proteins were transferred to nitrocellulose membrane and bands were visualized with enhanced chemiluminescence reagents (GE Healthcare).

CSPG binding assays in COS-7 cells. COS-7 cells were grown as described above. Cells cultured on poly-L-lysine-coated 96-well plates were transfected with a control DNA, LAR-WT, LAR with the D2 domain deletion mutant $\triangle \mathrm{D} 2$, or LAR mutant $\mathrm{C} 1522 \mathrm{~S}$ containing a cysteine-toserine missense mutation in the D1 domain (Dunah et al., 2005). Fortyeight hours after transfection, cells were incubated with a mixture of purified CSPGs containing neurocan, versican, phosphacan, and aggrecan $(5.2 \mu \mathrm{g} / \mathrm{ml}$; Millipore) for $2 \mathrm{~h}$. These CSPGs are highly upregulated around the lesion several days to weeks after a CNS injury and significantly contribute to the growth failure of injured axons (Jones et al., 2003; Carulli et al., 2005). In selected experiments, transfected COS-7 cells were incubated with CSPGs in the presence of ChABC to digest the GAG chains. Following three washes with PBS, CSPG binding signals to COS-7 cells were detected via immunostaining. In brief, after blocking nonspecific binding sites with 10\% goat serum in PBS for $30 \mathrm{~min}$, fixed COS-7 cells were incubated with a mouse monoclonal antibody against CSPGs (clone Cat-316; Millipore) followed by a biotin-conjugated goat anti-mouse secondary antibody (Lander et al., 1997). After five washes with PBS, cells were treated with avidin-biotin peroxidase complex 
(ABC) for $60 \mathrm{~min}$, and CSPG binding signals were visualized with ABCdiaminobenzidine (DAB)-based reaction. The intensity of reaction color in multiple wells was read with a 96-well plate reader at $405 \mathrm{~nm}$.

Quantitative binding assay of CSPG to LAR protein in COS-7 supernatants was performed with immobilized LAR coated onto 96-well assay plates via ELISA. COS-7 cells were cultured in $60 \mathrm{~mm}$ dishes and transfected with vehicle, LAR-WT, or LAR mutant $\Delta \mathrm{D} 2$. After $48 \mathrm{~h}$ transfection, cells were washed with ice-cold PBS three times and prepared in 300 $\mu \mathrm{l}$ of cold lysis buffer supplemented with protease inhibitors. Following clarification via centrifugation at $15,000 \times g$ for $10 \mathrm{~min}$ at $4^{\circ} \mathrm{C}$ and total protein quantification with Bio-Rad DC protein assay reagents, $25 \mu \mathrm{l}$ of supernatant samples containing the same concentration of protein were added to 96-well plates and incubated for $1 \mathrm{~h}$ at room temperature. After two washes with PBS, wells were treated with a mixture of purified CSPGs $(5.2 \mu \mathrm{g} / \mathrm{ml})$ for $2 \mathrm{~h}$ at $37^{\circ} \mathrm{C}$. Following five washes with PBS and fixation with $4 \%$ formalin, coated proteins on wells were blocked with $10 \%$ goat serum for $30 \mathrm{~min}$ and treated with a mouse antibody against CSPG followed by a biotin-conjugated anti-mouse secondary antibody. CSPG binding signals to LAR in the cell supernatants were detected with ABCDAB-based reaction as above. All the binding experiments in the transfected cells were performed in 5-10 replicates.

PTP activity assay in COS-7 cells. COS-7 cells were grown in 24-well plates and transfected with LAR-WT, LAR mutations, or control DNA as above. Two days after transfection, cells were washed with phosphatefree saline two times and prepared in phosphate-free lysis buffer supplemented with $1 \mathrm{~mm}$ phenylmethylsulfonyl fluoride, $10 \mu \mathrm{g} / \mathrm{ml}$ leupeptin, $10 \mu \mathrm{g} / \mathrm{ml}$ aprotinin, and a protease inhibitor mixture (Sigma-Aldrich). Then, $30 \mu \mathrm{l}$ of cell lysates were treated with purified CSPGs $(7.5 \mu \mathrm{g} / \mathrm{ml}$; Millipore) or purified chondroitin sulfate (CS) $(400 \mu \mathrm{g} / \mathrm{ml}$; SigmaAldrich) for $3 \mathrm{~min}$ at room temperature. The same amount of samples from each well was also treated with vehicle for $3 \mathrm{~min}$. The PTP activity in samples after stimulation with CSPG, CS, or vehicle was measured via a nonradioactive phosphotyrosine phosphatase assay using PTP-101 kit (Sigma-Aldrich). This assay measures the levels of phosphate generated from PTP reaction in the presence of insulin receptor phosphopeptides, the substrates of PTP including LAR. The PTP activity in each well was determined by calculating the ratio of PTP activity in the presence and absence of CSPGs or CS.

LAR knock-out mice. LAR knock-out mice were provided by F. M. Longo (Xie et al., 2001) and $\mathrm{LAR}^{+/-}$littermate crosses were used to generate $\mathrm{LAR}^{+/+}, \mathrm{LAR}^{+/-}$, and LAR ${ }^{-1-}$ littermates. Genotyping was conducted via reverse transcription-PCR following the protocols from the laboratory of F. M. Longo (Xie et al., 2001). Homozygous and heterozygous LAR mutant mice are viable and grossly normal in appearance. The LAR knock-out mice contain a $\beta$-galactosidase/neomycin ( $\beta$ geo) reporter transgene in the intron between exons 6 and 7 of LAR gene. This transgene contains an En-2 splice acceptor that functions as a "gene trap" and results in expression of a fusion protein containing a small segment of LAR extracellular $\mathrm{N}$-terminal (the first two Ig-like domains) and $\beta$-geo protein (Xie et al., 2001). The LAR/ $\beta$-geo fusion protein omits $>90 \%$ of the LAR protein domains, including most of the extracellular region (the third Ig-like domain along with eight FNIII domains) and the entire intracellular region (including phosphatase domains).

Neurite growth assay in primary neuronal cultures. The neurite outgrowth from neurons was performed in dorsal root ganglion (DRG) and cerebellar granular neuron (CGN) cultures $24 \mathrm{~h}$ after growth. In some cases, coverslips were coated with a mixture of purified CSPGs $(1.5 \mu \mathrm{g} /$ $\mathrm{ml}$; Millipore) or CNS myelin ( $50 \mu \mathrm{g} / \mathrm{ml})$. DRGs were dissected out from different genotypes of LAR mutant mice or from C57BL/6 mice (for peptide experiments) aged 7-10 weeks. After incubation with collagenase and $0.25 \%$ trypsin/EDTA and washing with culture medium, dissociated DRG neurons were plated onto plastic coverslips in 24-well plates and grown in culture medium (DMEM/F12 mixture plus 10\% fetal bovine serum, $2 \mathrm{~mm}$ glutamine, $100 \mu \mathrm{g} / \mathrm{ml}$ penicillin, and $100 \mu \mathrm{g} / \mathrm{ml}$ streptomycin) for $24 \mathrm{~h}$ or $4 \mathrm{~d}$ at $37^{\circ} \mathrm{C}$ (Fu et al., 2007; Dill et al., 2008).

Primary cerebellar granular neuron cultures were prepared from cerebelli of postnatal 7-9 d C57BL/6 mice. After trypsin digestion, cells were dissociated and grown in culture medium (DMEM/F12 containing 10\% fetal bovine serum, $2 \mathrm{~mm}$ glutamine, $100 \mu \mathrm{g} / \mathrm{ml}$ penicillin and $100 \mu \mathrm{g} / \mathrm{ml}$ streptomycin, $25 \mathrm{~mm} \mathrm{KCl}$, and $25 \mathrm{~mm}$ glucose) for $24 \mathrm{~h}$ at $37^{\circ} \mathrm{C}$. After coating with poly-L-lysine $(100 \mu \mathrm{g} / \mathrm{ml})$, cell culture coverslips were incubated with $10 \mu \mathrm{g} / \mathrm{ml}$ laminin for $2 \mathrm{~h}$ at $37^{\circ} \mathrm{C}$ before cell plating. NGF was not applied to neuronal cultures for neurite outgrowth assays.

After cell plating, dissociated neurons were treated with vehicle, RP (7.5 $\mu \mathrm{M})$, ELP $(7.5 \mu \mathrm{M})$, or ILP $(2.5 \mu \mathrm{M})$. These peptides were synthesized by $\mathrm{CHI}$ Scientific, and their purity was analyzed via HPLC. For neurite outgrowth, neuronal cells were fixed $24 \mathrm{~h}$ after plating and stained with a mouse antibody against Tuj1. Images of each culture were captured with a Nikon image-collecting system, and neurite outgrowth was quantified with Photoshop and NIH Image software (GrandPré et al., 2002; Fu et al., 2007; Dill et al., 2008). For outgrowth quantification, the total neurite length for each neuron was determined from 40 to 150 representative DRG neurons or from 120 to 180 CGNs in each experiment. The mean values were calculated from four to six separate experiments.

Akt, CRMP2, and active RhoA assays in CGNs. The primary CGN cultures were prepared from cerebelli of postnatal 7-9 d LAR ${ }^{+/+}$or $\mathrm{LAR}^{-1-}$ mice. After $24 \mathrm{~h}$ growth, CGN cultures were incubated with CSPGs $(1.5 \mu \mathrm{g} / \mathrm{ml})$ for 2-30 min. After washing with ice-cold PBS, cells in each dish $(60 \mathrm{~mm})$ were prepared in $300 \mu \mathrm{l}$ of cold lysis buffer supplemented with protease inhibitors and clarified by centrifugation at $15,000 \times g$ for $10 \mathrm{~min}$ at $4^{\circ} \mathrm{C}$. Following total protein quantification in supernatants with Bio-Rad DC protein assay reagents, samples containing the same amount of proteins were prepared for Western blot using antibodies against phosphorylated Akt Ser473, CRMP2 Thr514, and total Akt or CRMP2. The levels of phosphorylated Akt and CRMP2 represent active Akt and inactive CRMP2, respectively. Proteins were transferred to nitrocellulose membrane, and bands were visualized with enhanced chemiluminescence reagents. The levels of GTP-bound RhoA in CGNs were measured via precipitation with RBD beads as we reported (Fu et al., 2007; Dill et al., 2010). For band densitometry, the images of Akt-p, CRMP2-p, and active RhoA bands were captured with a Bio-Rad Gel Doc XR documentation system, and band density was determined using Quantity One software (Fu et al., 2007). For each group, four separate experiments were performed, and the values of band density measured from cells collected at different time points were compared with those treated with vehicle PBS.

Dorsal transection lesions of the spinal cord, histology, and behavioral tests in SCI mice. Adult female C57BL/6 mice (8-10 weeks of age; The Jackson Laboratory) were deeply anesthetized with intramuscular ketamine $(100 \mathrm{mg} / \mathrm{kg})$ and intraperitoneal xylazine $(15 \mathrm{mg} / \mathrm{kg})$. A complete laminectomy was performed, and the dorsal part of the spinal cord was fully exposed at levels T6 and T7 (Li and Strittmatter, 2003). A dorsal over-hemisection was performed at T7 with a 30 gauge needle and a pair of microscissors to completely sever dorsal part of the spinal cord. The depth of the lesion $(1.0 \mathrm{~mm})$ was ensured by passing the marked needle several times across dorsal part of the spinal cord. The muscle layers over the laminectomies were sutured, and the skin on the back was closed with surgical staples. Two days after SCI, mice started to receive daily subcutaneous injections of vehicle DMSO (14 $\mu \mathrm{l}$ in $86 \mu \mathrm{l}$ of PBS per injection), ELP $(140 \mu \mathrm{g} /$ mouse per day), or ILP (75 $\mu \mathrm{g} /$ mouse per day) for 10 successive days with syringes at lower part of the hindquarters. These peptides were dissolved in DMSO first before diluted in sterile PBS. During the first $6 \mathrm{~d}$ after SCI, one to three mice died in each group due to poor general health. For axonal quantification and behavioral analysis, six, five, and eight mice were used in the control, ELP, and ILP groups, respectively.

Mice were perfused transcardially 5 weeks after SCI with PBS followed by $4 \%$ paraformaldehyde. After postfixation in the same fixative, transverse sections $(40 \mu \mathrm{m})$ were collected from the spinal cord 5-7 $\mathrm{mm}$ rostral to and 5-7 $\mathrm{mm}$ caudal to the injury center. To visualize serotonergic fibers, transverse sections of the spinal cord were stained with an antibody against 5-HT. To determine serotonergic fibers at the spinal cord 5-7 mm caudal to the lesion, individual fibers stained by 5-HT antibody in the ventral and dorsal half of the spinal cord were traced manually, and the mean density of traced 5-HT fibers was measured blindly from two random transverse sections in each mouse using NIH software. To further compare axon number in the caudal spinal cord among different groups, we counted 5-HT axons in the spinal cord 0-2.4 
$\mathrm{mm}$ caudal to the lesion epicenter from all the parasagittal sections in each animal ( $\sim 25$ sections per mouse) in a blind manner. The lesion center was determined based on the characteristic staining patterns for glial fibrillary acidic protein and cavitations around the injury. To determine whether treatments with peptides benefit functional recovery after SCI, we evaluated locomotion recovery during 5 weeks of survival by measuring the Basso mouse scale for locomotion (BMS) $2 \mathrm{~d}$ and per week after SCI and the grid walk performance 5 weeks after SCI.

Statistical analysis. SigmaPlot software was used for statistical analysis. Data are shown as means \pm SEM in the graphs. A repeated-measures ANOVA was used for the BMS data analysis. Statistical significance for other analyses was tested with the unpaired Student's $t$ test with Welch's correction or Mann-Whitney modification. The differences with $p<$ 0.05 were considered significant between different groups.

\section{Results}

\section{Neuronal expression of LAR in the brain and spinal cord and} coimmunoprecipitation of LAR with CSPG

If LAR is a functional receptor for CSPGs, LAR protein should be widely expressed in various neurons in the adult CNS. We analyzed LAR expression using a rabbit polyclonal antibody against the intracellular domain (amino acids 1081-1150) of human origin LAR. Immunohistochemistry revealed the wide expression of LAR protein in different populations of neurons in the brain and spinal cord, including axonal cylinders along the white matter tracts (Fig. $1 A, C$ ). In contrast, LAR knock-out mice did not exhibit any obvious LAR staining signal in the CNS, suggesting the selectivity of this LAR antibody (Fig. $1 B, D$ ). Of note, NeuNpositive neurons were present in the white matter tracts of the brain (Fig. 1A,B) (Loup et al., 2009). To confirm LAR protein expression in wild-type mice, we examined the levels of this protein via Western blots with an antibody against the $\mathrm{N}$-terminal sequence (24-196) of human LAR. In $\mathrm{LAR}^{+/+}$mice, we detected LAR protein at $150 \mathrm{kDa}$ from the spinal cord and brain (data not shown). This $150 \mathrm{kDa}$ band appears to represent three Ig domains and eight Fn III domains of the E-subunit of LAR (Tsujikawa et al., 2001).

The membrane protein LAR has been reported to bind several extracellular ligands including syndecan and Dallylike, two heparan sulfate proteoglycans (HSPGs), at the neuromuscular junction in flies (Fox and Zinn, 2005; Johnson et al., 2006). LAR interacts with the GAG chains of syndecans with nanomolar affinity and regulates syndecan-dependent presynaptic growth. Similar to CSPGs, syndecans structurally possess an extracellular core protein and long GAG side chains (repeating sulfated disaccharide units). Functionally, both HSPGs and CSPGs play a role in guiding axons during neuronal development (Van Vactor et al., 2006). For example, HSPGs contribute to growth cone collapse induced by Ephrin-A3 in mouse cortical neurons (Irie et al., 2008). Considering structural and functional similarities between CSPGs and HSPGs, we have hypothesized that CSPGs repress axonal elongation of mature neurons principally via interaction with membrane LAR on the axons. Co-IP has been widely used to detect protein interaction. To determine potential interaction between CSPGs and LAR in vivo, we performed co-IP for LAR in supernatants of several tissue sources and precipitated LAR components by immunoblotting for CSPG molecule versican. From all the supernatants of tissues, including the injured spinal cord, uninjured spinal cord, brain, aorta, and lung, we pulled down two major bands for versican, the $150 \mathrm{kDa}$ core protein and $70 \mathrm{kDa}$ $\mathrm{N}$-terminal cleavage fragment (Fig. $1 E$ ) (Y. Zhang et al., 1998). In some supernatants of tissues, including lung and injured spinal cord, we also detected a weak band of $220 \mathrm{kDa}$. Previous studies confirmed the identity of $220 \mathrm{kDa}$ versican fragment from mam- malian tissue extracts (Sandy et al., 2001). Using Western blot, we confirmed the high level expression of LAR protein (Fig. $1 E$ ) and this CSPG (data not shown) in various tissues. Thus, these experiments suggest that high levels of extracellular CSPGs, including versican, interact with neuronal LAR in the normal or injured CNS.

\section{CSPGs bind LAR phosphatase in COS-7 cells with high affinity}

To confirm interaction between CSPGs and LAR in vitro, we performed a CSPG binding assay for LAR expressed in nonneuronal COS-7 cells $48 \mathrm{~h}$ after transfection. After incubation with a purified CSPG mixture ( $5.2 \mu \mathrm{g} / \mathrm{ml} ; \sim 20 \mathrm{~nm})$, CSPG binding signal was visualized with biotin-conjugated secondary antibody and ABC-DAB-based reactions. In non-transfected COS-7 cells, we detected weak baseline staining probably due to a low level of CSPG expression in COS-7 cells. However, cells transfected with LAR-WT DNA exhibited dramatically enhanced signals for CSPG staining (Fig. $2 B, F$ ), especially in the cytoplasmic membrane areas (Fig. 2C). Our result indicates that the affinity is due to LAR expression in COS-7 cells (Fig. 2D). Dose-response curves indicate that CSPG binding signal increases in a dosedependent manner (Fig. 2G) and reaches its maximal level at $\sim 7.5 \mu \mathrm{g} / \mathrm{ml}$ CSPGs $(\sim 30 \mathrm{~nm})$.

The intracellular D2 domain of LAR has been shown to regulate binding of ligands, including Liprin- $\alpha$ and the insulin receptor (Serra-Pagès et al., 1998; Tsujikawa et al., 2001). To determine whether the D2 domain of LAR contributes to CSPG binding in cell cultures, we overexpressed a LAR mutation with deleted D2 domain $(\Delta D 2)$ (Dunah et al., 2005). This mutated construct has been reported to disrupt the interaction of endogenous LAR with Liprin- $\alpha$, a family of proteins recruiting synaptic proteins and regulating synaptic cargo transport during synaptic maturation. In contrast, $\mathrm{C} 1522 \mathrm{~S}$ mutation in the $\mathrm{D} 1$ domain inactivates catalytic activity of LAR, but does not have any effect on the bindregulating domain D2 (Dunah et al., 2005). We found that COS-7 cells transfected with $\Delta \mathrm{D} 2$ mutation exhibited significantly reduced CSPG binding compared with those transfected with LARWT. Transfection with the D1 domain mutant C1422S did not affect the binding of CSPGs to LAR protein (Fig. $2 B, F$ ). The GAG chains have been reported to play a critical role in regulating axonal growth inhibition of CSPGs (Snow et al., 1990; Bradbury et al., 2002; Cafferty et al., 2007). We next tested whether the GAG chains participate in CSPG binding to LAR protein by removing GAGs from the core protein via ChABC digestion. Incubation with CSPGs $(4.5 \mu \mathrm{g} / \mathrm{ml})$ increased CSPG binding signal in COS-7 cells transfected with LAR-WT, but treatments with CSPGs plus ChABC significantly attenuated the binding signals of CSPGs to LAR in transfected COS-7 cells (Fig. $2 \mathrm{H}$ ).

Recently, a study reported that CSPGs interact with RPTP $\sigma$ through a basic motif in the first Ig-like domain (Shen et al., 2009). Given that RPTP $\sigma$ is also a member in the LAR subfamily and has an almost identical domain organization with LAR, we next examined whether the first Ig-like domain of LAR would play a role for mediating CSPG binding to LAR. We generated a point mutation by changing lysine residues $\mathrm{K} 68, \mathrm{~K} 69, \mathrm{~K} 71$, and $\mathrm{K} 72$ to alanines in the first Ig domain of LAR (Shen et al., 2009). As shown in Figure 2I, the mutated LAR in Ig-like-1 domain (LAR Ig1M) significantly reduced the CSPG binding signals in COS-7 cells $48 \mathrm{~h}$ after transfection. Thus, this experiment indicates that the first Ig-like domain of LAR also contributes to the CSPG binding to LAR.

To confirm the interaction between CSPGs and LAR, we also evaluated the binding of purified CSPGs to the supernatants of 



E

LAR CO-IP with versican

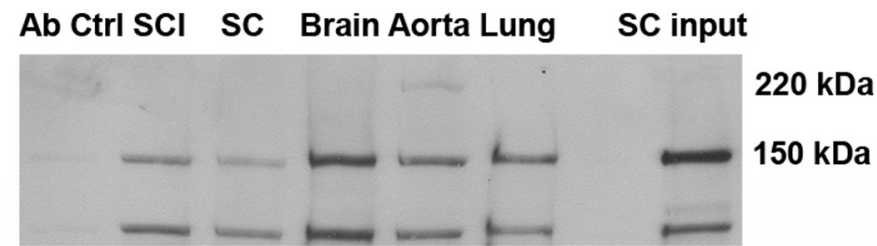

\section{LAR protein in tissue lysates}

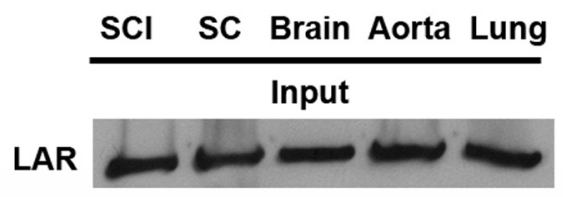

Figure 1. LAR is highly expressed in CNS neurons and coimmunoprecipitated with CSPG versican in various tissue supernatants. $\boldsymbol{A}, \boldsymbol{C}, \mathrm{LAR}$ is expressed in different populations of neurons in the gray matter (GM) areas and white matter (WM) tracts of the brain and spinal cord derived from wild-type mice. Neuronal marker NeuN and axonal marker neurofilament (NF) were used to label neuronal bodies and axon cylinders, respectively. $\boldsymbol{B}, \boldsymbol{D}, \mathrm{LAR}$ staining signals are absent in the gray matter areas and white matter tracts of the brain and spinal cord in LAR ${ }^{-1-}$ mice. Scale bars: $\boldsymbol{A}_{\text {, }}$ $\boldsymbol{B}, 50 \mu \mathrm{m} ; \boldsymbol{C}, \boldsymbol{D}, 25 \mu \mathrm{m}$. $\boldsymbol{E}$, LAR was coimmunoprecipitated with CSPG versican in the supernatants of different tissues from wild-type mice using antibodies against LAR (IP) and versican (blot). LAR protein was detected from these tissue lysates (bands on the right).

cells transfected with vehicle, LAR-WT or $\Delta \mathrm{D} 2$ mutation. We incubated 96-well plates with COS-7 cell supernatants at the same protein concentrations and then with purified CSPGs (5.2 $\mu \mathrm{g} / \mathrm{ml})$. After five washes, CSPG binding signals were detected via an ELISA. Consistently, the supernatants of cells transfected with LAR-WT displayed remarkably enhanced CSPG binding signals than those from control and $\Delta \mathrm{D} 2$ mutation (Fig. $2 J$ ). Western blot analysis confirmed expression of LAR protein in COS-7 cells transfected with LAR-WT $(220 \mathrm{kDa})$ or the D2 mutation (a shifted band $<220 \mathrm{kDa}$ ) (Fig. $2 \mathrm{~K}$ ). Immunostaining displayed high levels of LAR-WT (Fig. 2D) and LAR D2 mutant (Fig. 2E) proteins in LAR-transfected COS-7 cells, including the cytoplasmic membrane areas. We also performed co-IP experiments with COS-7 cell supernatants and purified CSPGs. Consistently, LAR 
A

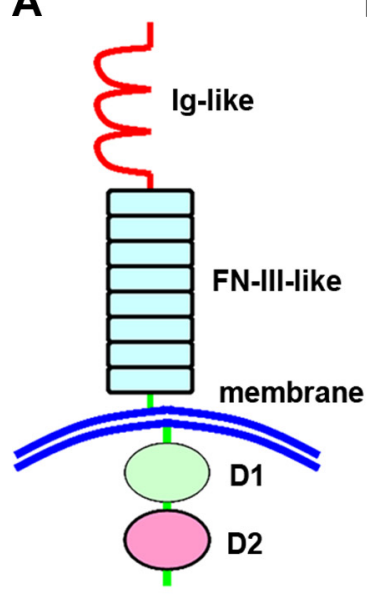

E
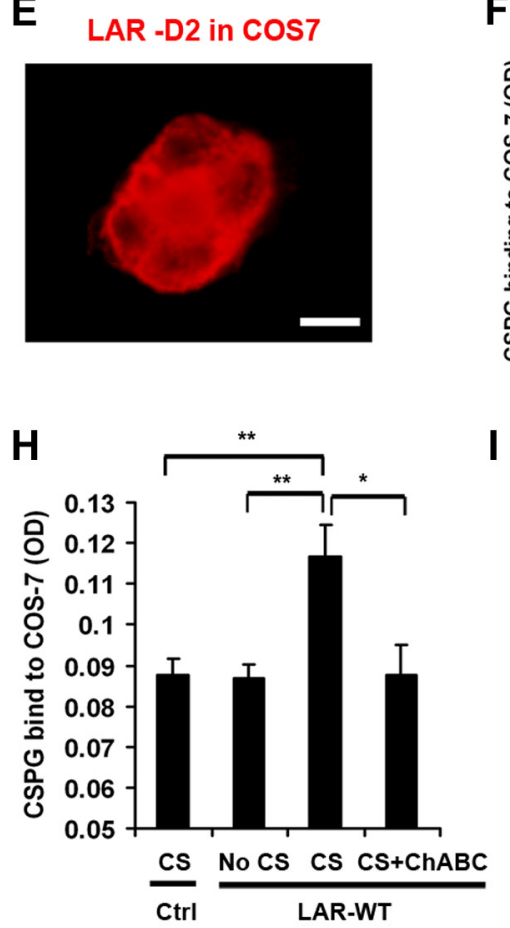

B

F

I

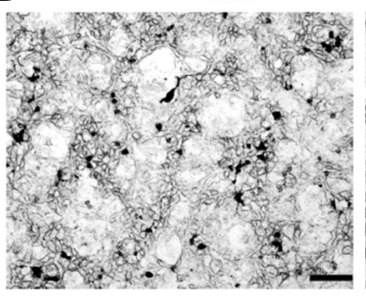

LAR-DeltaD2
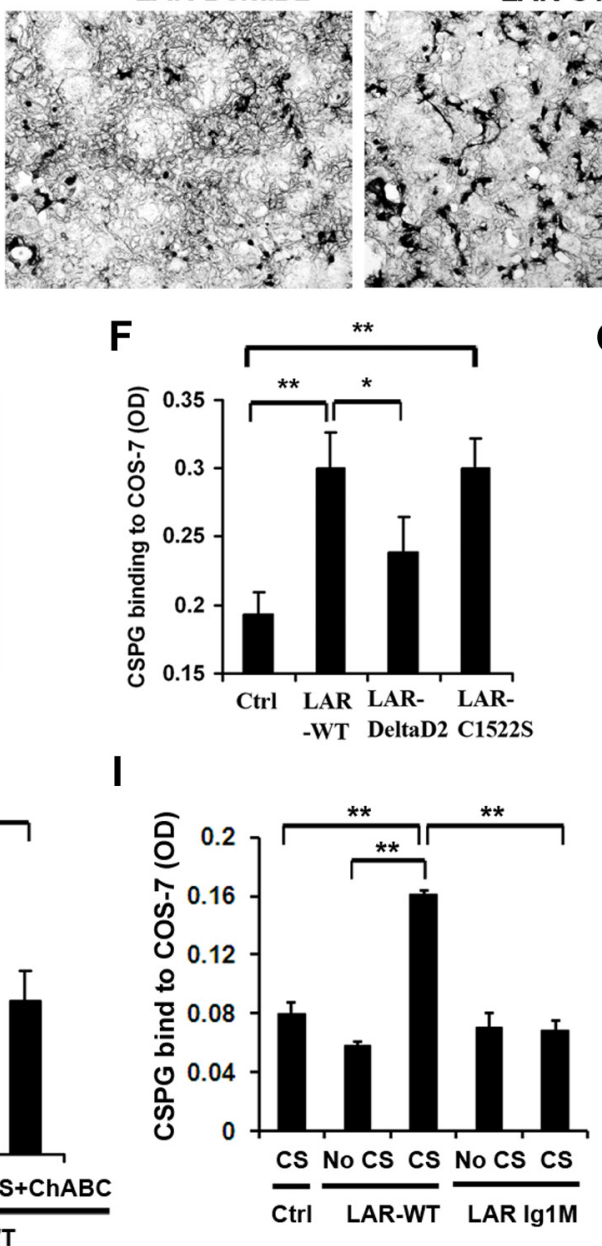

LAR-WT

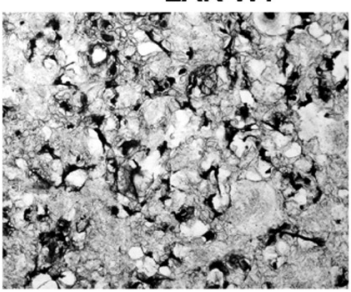

LAR-C1522S

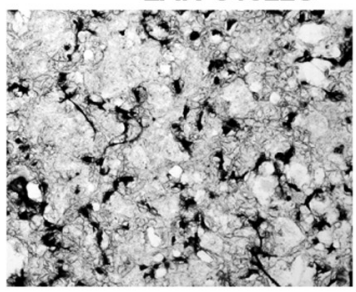

G

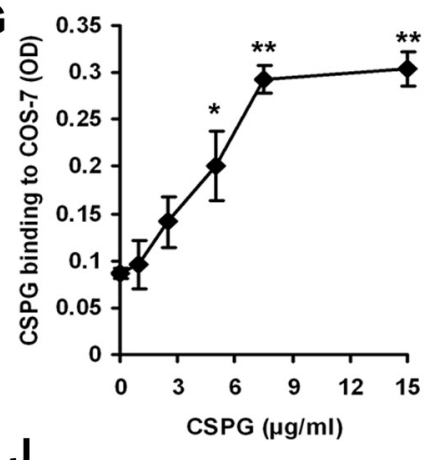

J

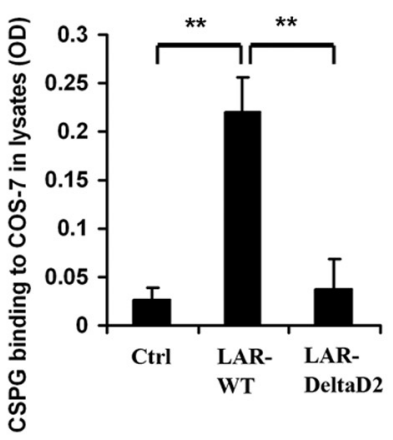

K LAR expression in COS-7

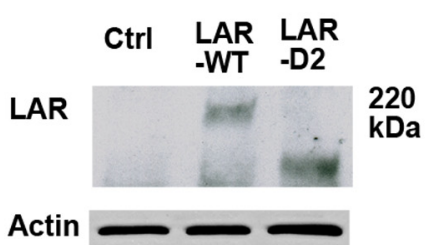

L LAR Co-IP with neurocan

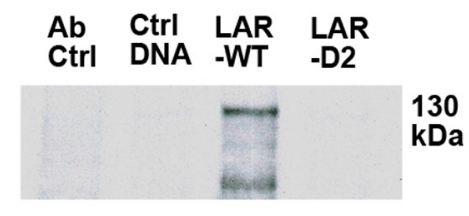

Figure 2. CSPGs bind LAR protein with high affinity in COS-7 cells. $A$, Schematic diagram indicates the LAR transmembrane protein. LAR ectodomain includes several Ig-like and fibronectin type-III domains. Its intracellular portion consists of two cytosolic phosphatase domains called D1 and D2.B, COS-7 cells were transfected with control, LAR-WT, LAR mutant with D2 domain deletion $(\triangle D 2)$, or LAR mutant with D1 domain mutation (C1522S). Forty-eight hours after transfection, cells were incubated with purified CSPGs and CSPG-binding signal was detected via immune-based staining. Scale bar, $100 \mu \mathrm{m}$. C, Image at high magnification indicates CSPG binding signal to COS-7 transfected with LAR-WT. Scale bar, $25 \mu \mathrm{m}$. D, Immunostaining for LAR indicates LAR expression in COS-7 cells $48 \mathrm{~h}$ after transfection. Scale bar, $50 \mu \mathrm{m}$. E, Immunostaining for LAR $\triangle \mathrm{D} 2$ indicates expression of this mutated LAR in COS-7 cells $48 \mathrm{~h}$ after transfection. Scale bar, $50 \mu \mathrm{m}$. $F$, Bar graph indicates CSPG binding signal for COS-7 cells in 96-well plates. The binding signal was quantified in each group with a plate reader at $405 \mathrm{~nm}$. $n=6$ wells in each group. $\mathbf{G}$, A dose-response curve for CSPG binding was determined in COS-7 cells transfected with LAR-WT. $\boldsymbol{H}, \boldsymbol{I}$, The bar graphs indicate CSPG binding signals to COS-7 cells quantified from 96 -well plates with a plate reader at 405 $\mathrm{nm} . n=6-10$ wells in each group. CS, CSPG. LAR Ig1M, LAR mutation in the first Ig-like domain. J, The affinity of CSPG interaction with LAR was determined from the supernatants of COS-7 cells via an ELISA. $\boldsymbol{K}$, Western blot indicates expression of LAR protein in COS-7 cells transfected with LAR-WT, but not in the control. COS-7 cells transfected with $\triangle D 2$ mutation exhibit a reduced band size for LAR. L, LAR conjugated to c-myc in COS-7 supernatants was coimmunoprecipitated with CSPG neurocan using antibodies against c-myc (IP) and neurocan (blot). In $F-J$, ${ }^{*} p<0.05,{ }^{* *} p<$ 0.01 , Student's $t$ test. Error bars indicate SEM. 
A

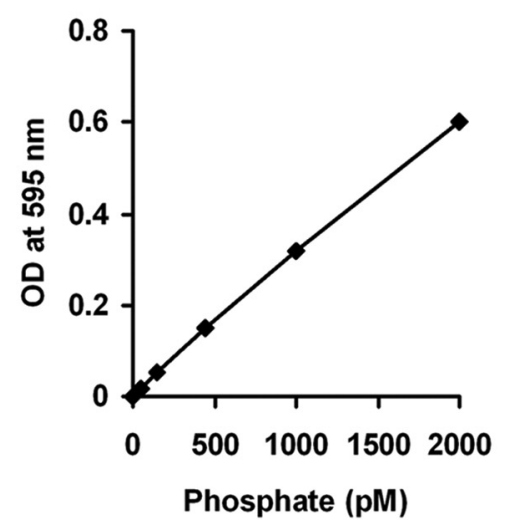

B

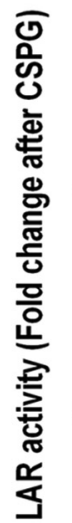

$C_{\overparen{B}}$

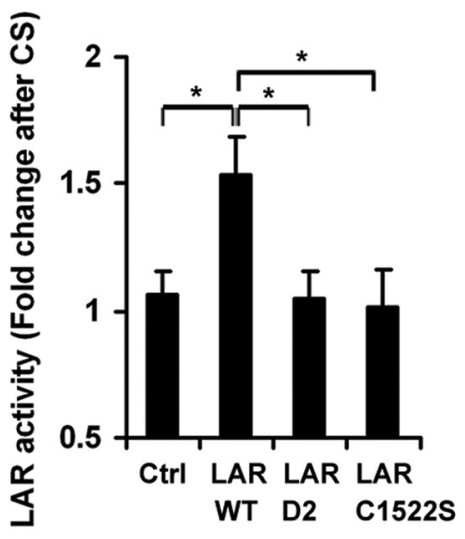

Figure 3. CSPGs and chondroitin sulfate activate LAR phosphatase in COS-7 cells. $A$, A dose-response curve indicates the high correlation between color changes (0D at $595 \mathrm{~nm})$ and phosphate gradients. B, C, The bar graphs indicate that stimulation with CSPG $(7.5 \mu \mathrm{g} / \mathrm{ml})$ or CS (400 $\mu \mathrm{g} / \mathrm{ml})$ increases LAR activity (fold changes after CSPGs or CS) in COS-7 cells transfected with LAR-WT, but not with LAR mutants $\Delta$ D2 or C1522S. $n=6$ wells per group in $B$ and $C$. ${ }^{*} p<0.05,{ }^{* *} p<0.01$, Student's $t$ test. Error bars indicate SEM.

protein was robustly coprecipitated with CSPG detected by an antibody against neurocan, one of the lecticans highly expressed in the injured CNS (Jones et al., 2003). Together, these experiments suggest that CSPGs bind LAR protein with high affinity and that the LAR D2 domain contributes to the binding of CSPGs to LAR phosphatase.

\section{CSPGs and chondroitin sulfate enhance LAR phosphatase activity in COS-7 cells}

If LAR mediates the growth-inhibitory nature of CSPGs by acting as their functional receptor, stimulation of LAR with CSPG molecules should alter the activity of LAR phosphatase. We tested this hypothesis by measuring LAR activity in COS-7 cells transfected with either LAR-WT or LAR mutations. Two days after transfection, COS-7 cells were prepared in phosphate-free lysis buffer and cell lysates were incubated with a mixture of purified CSPGs $(7.5 \mu \mathrm{g} / \mathrm{ml} ; 3 \mathrm{~min})$ or with chondroitin sulfate $(400 \mu \mathrm{g} / \mathrm{ml} ; 3$ $\mathrm{min})$, the component of sulfated glycosaminoglycans that can mimic the suppressive features of CSPGs by inducing growth cone collapse and inhibiting axonal extension (Ughrin et al., 2003; Wang et al., 2008). LAR activity in cell lysates was determined with a PTP kit by monitoring colorimetric changes of free phosphate generated by PTP-based dephosphorylation reactions in the presence of a substrate. To confirm the reliability of this measuring system, we first obtained a dose-response curve using a standard phosphate solution. As shown in Figure $3 A$, the color reactions in 96-well plates are linearly correlated to phosphate concentrations. Next, we measured concentrations of phosphate generated by dephosphorylating an insulin receptor peptide substrate in the presence of COS-7 cell lysates. Stimulation with CSPGs or CS significantly increased PTP activity in the lysates of cells transfected with LAR-WT compared with the cells transfected with a control DNA (Fig. $3 B, C$ ). However, CSPGs and CS, the major inhibitory component of CSPGs, failed to induce such an effect in the lysates of cells transfected with the D1 (C1522S) and D2 mutations of LAR, which mutated the enzymatic activity domain and deleted the binding-recognizing domain of LAR, respectively. Our data suggest that CSPGs and CS are able to activate LAR phosphatase in vitro.

LAR deletion in knock-out mice overcomes growth restriction of CSPGs on neurites in neuronal cultures

If binding of CSPGs to LAR mediates CSPG suppression, LAR deletion should attenuate the inhibitory function of CSPGs on axon growth. To test this hypothesis, we evaluated LAR protein deletion on neurite outgrowth from cultured DRG neurons exposed to a mixture of purified CSPGs, which contains neurocan, versican, phosphacan, and aggrecan. These CSPGs are highly upregulated in the lesioned CNS (Jones et al., 2003; Sherman and Back, 2008). Although the number of progeny in $\mathrm{LAR}^{-1-}$ mice is significantly lower than that of $\mathrm{LAR}^{+/+}$mice (17 vs 25\%) (Yeo et al., 1997), $\mathrm{LAR}^{-1-}$ and $\mathrm{LAR}^{+/-}$mice are viable and grossly normal in appearance. Morphologically, $\mathrm{LAR}^{-/-}$mice exhibit significantly reduced size of basal forebrain cholinergic neurons and loss of cholinergic innervation to their target neurons in the dentate gyrus (Yeo et al., 1997). Behavioral evaluations of mice lacking LAR phosphatase domains exhibit spatial learning impairment and increased activity (Kolkman et al., 2004). In adult wild-type mice, DRG neurons express high level of LAR protein (Xie et al., 2001), but morphological analyses of DRGs in $\mathrm{LAR}^{-1-}$ mice indicate normal overall appearance, fiber density, axonal area, and myelin area (Xie et al., 2001). Functional evaluation of sensory pathways via pain withdrawal responses shows no differences in phenotype between $\mathrm{LAR}^{+/+}$and $\mathrm{LAR}^{-/-}$littermate mice. As we expected, application of CSPGs $(1.5 \mu \mathrm{g} / \mathrm{ml})$ remarkably attenuated the length of neurites in dissociated DRG neurons derived from adult $\mathrm{LAR}^{+/+}$or $\mathrm{LAR}^{+/-}$mice $24 \mathrm{~h}$ after growth. However, DRG neurons derived from adult $\mathrm{LAR}^{-1-}$ mice exhibit significantly increased neurite length when cultured on CSPG substrates (Fig. $4 A, B$ ). The remaining CSPG suppression in $\mathrm{LAR}^{-/-} \mathrm{DRG}$ neurons appears to be regulated by additional receptors, such as RPTP $\sigma$ (Shen et al., 2009), or non-receptor-mediated mechanism. These results demonstrate that LAR protein mediates growth repression of CSPG molecules in mature neurons.

\section{LAR selective blockade with sequence-targeting peptides} overcomes growth restriction of CSPGs on neurites

To confirm that functional blockade of LAR attenuates CSPG suppression on neurite elongation, we next used two LAR binding peptides derived from the LAR extracellular and intracellular domains, respectively. ELP contains 37 residues corresponding to the fifth LAR fibronectin type III (FN-III) domain and blocks LAR homophilic interaction by binding the same LAR domain (Yang et al., 2005). ILP has 35 aa including 24 residues derived from the wedge-shaped helix-loop-helix sequence located between the membrane proximal region and the D1 catalytic domain (Xie et al., 2006). The C-terminal of ILP contains a 


\section{Neurite growth in DRG neurons}
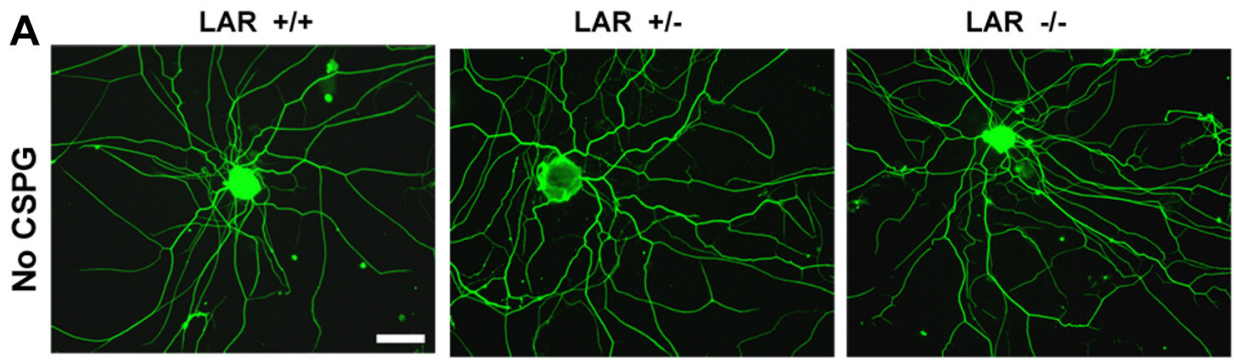

B
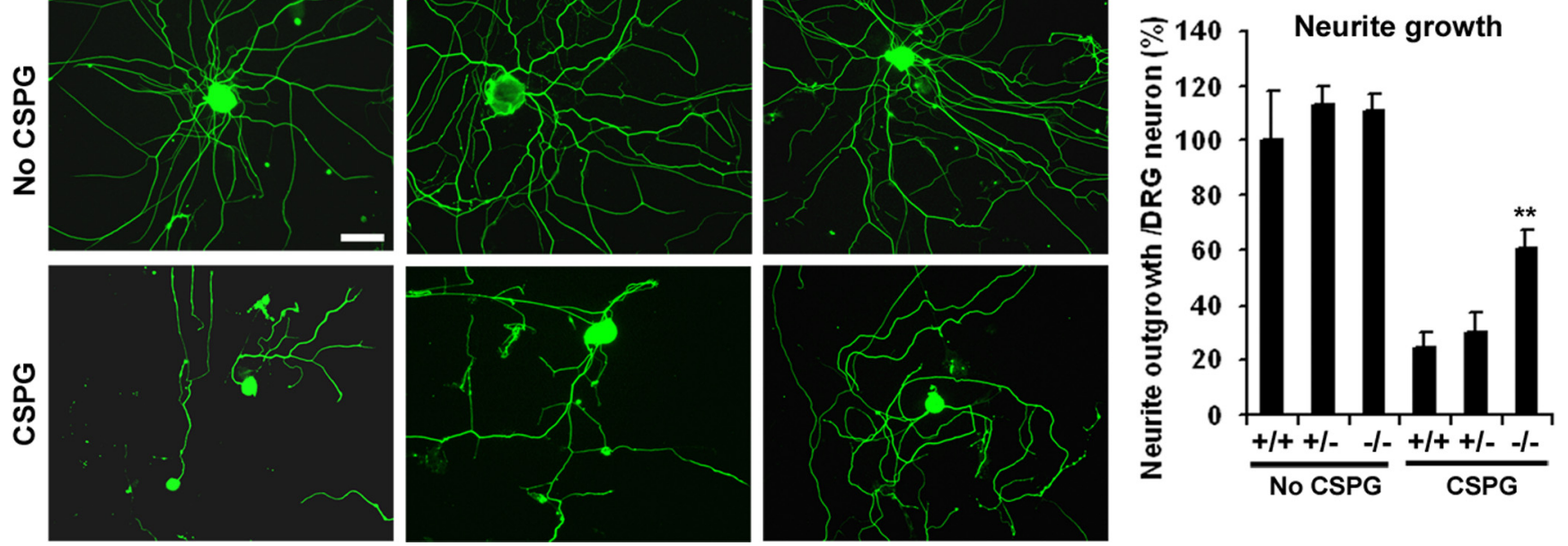

Figure 4. LAR deletion in mutant mice significantly reverses neurite outgrowth in DRG neurons cultured on CSPGs. $A_{\text {, DRG neurons derived from adult LAR }}^{+/+}$, LAR $^{+/-}$, or LAR ${ }^{-/-}$mice were cultured in the absence or presence of CSPGs $(1.5 \mu \mathrm{g} / \mathrm{ml})$. Neurons were fixed and stained with an antibody against $\beta$ III-tubulin $24 \mathrm{~h}$ after growth. DRG neurons derived from LAR ${ }^{-/-}$mice remarkably recovered neurite length of DRG neurons on CSPGs. Scale bar, $50 \mu \mathrm{m}$. B, Neurite length per DRG neuron was quantified $24 \mathrm{~h}$ after cell plating. LAR deletion increased neurite length in the presence of CSPGs compared with cells from control mice. The numbers indicate means \pm SEM from four coverslips ( $31-40$ images/coverslip) in each group. ${ }^{* *} p<0.01$, compared with $L_{A R}{ }^{+/+}$group in the presence of CSPGs, Student's $t$ test.

membrane-penetrating sequence (GRKKRRQRRRC) derived from the transactivator of transcription (TAT) peptide. Given that TAT-fusion proteins retain their biological activity and are able to rapidly and efficiently access the intracellular space of cultured cells and intact tissues following in vitro and in vivo extracellular applications (Schwarze et al., 1999; Futaki et al., 2001), the TAT-containing ILP should efficiently penetrate into cells after extracellular administration. ILP may block LAR functions by selectively interfering with the access of LAR substrates to the D1 enzymatic site and interaction of D1 domains with other important LAR regions and/or intracellular functional proteins (Xie et al., 2006). Studies from the group of F. M. Longo support efficient binding of ELP and ILP to LAR domains because ILP could precipitate the full-length LAR protein in vitro and administration of ELP and LIP stimulated neurite outgrowth of PC12 cells or embryonic neurons in cultures (Yang et al., 2005; Xie et al., 2006). We next examined the effect of LAR functional interference with these peptides on neurite outgrowth from cultured DRG neurons exposed to purified CSPGs. CSPGs remarkably attenuated the number and length of neurites in dissociated DRG neurons derived from adult C57BL/6 mice $24 \mathrm{~h}$ after growth (Fig. $5 A, E)$. As predicted, treatments with ELP $(7.5 \mu \mathrm{M})$ or ILP $(2.5 \mu \mathrm{M})$ significantly increased neurite length of DRG neurons cultured on CSPG substrates. To examine whether ELP and ILP overcome growth suppression selectively induced by CSPGs, we assessed the effects of these peptides on neurite growth of DRG neurons in the absence of any axonal growth inhibitors as well as in the presence of inhibitory substrates other than CSPGs. We demonstrate that ELP and ILP did not significantly alter neurite outgrowth of DRG neurons in the absence of axon growth inhibitors (Fig. $5 F$ ) or in the presence of CNS myelin inhibitors (Fig. 5G).

To explore the role of LAR activation in limiting axonal elongation in central neurons, we assessed neurite growth in cultured CGNs derived from postnatal 7-9 d mice (Dill et al., 2008). Like DRG neurons, the CGNs treated with ELP or ILP dramatically overcame growth suppression of CSPGs $24 \mathrm{~h}$ after cell plating
(Fig. 5C,H). While ELP and ILP target different domains of LAR, both induced a similar degree of neurite extension in neurons cultured on CSPG inhibitors. The remaining CSPG suppression after LAR peptide treatments might be regulated by additional receptors, such as RPTP $\sigma$ (Shen et al., 2009). Immunostaining for LAR indicates LAR protein expression in the soma and neurites of DRG neurons and CGNs (Fig. $5 B, D$ ). These experiments suggest that targeting LAR rather than other members of the RPTP family mediates the growth-enhancing activity detected here and that LAR activation contributes to neurite growth suppression of CSPGs.

Akt and RhoA mediate the downstream signaling pathways of CSPG-LAR interaction in neurons

Our results indicate that CSPGs enhance LAR phosphatase activity in vitro. We next determined the intracellular downstream signaling mechanisms by which CSPG-LAR interaction might mediate axonal growth inhibition. Our recent studies, together with other reports, indicate that Akt and RhoA signals contribute to CSPG-mediated growth suppression of neurons (Monnier et al., 2003; Fu et al., 2007; Dill et al., 2008). Thus, we evaluated whether LAR deletion alters activities of Akt and RhoA by measuring phosphorylated Akt (Akt-p) (Ser473) and active RhoA in cultured CGNs following CSPG incubation. By using CGN cultures, we could easily collect enough samples for Western blotting analysis. Phosphorylated Akt at residue Ser473 in its C-terminal hydrophobic motif is necessary for full activation of Akt and the cellular levels of Akt-p at Ser473 correlate with the activity of this kinase (Zhou et al., 2004; Chadborn et al., 2006). Following $24 \mathrm{~h}$ of growth, CGNs were treated with CSPGs (1.5 $\mu \mathrm{g} / \mathrm{ml}$ ) for 2-30 min and the levels of Akt-p and active RhoA in supernatants were detected via Western blot or precipitation with RBD beads. Application of CSPGs at $1.5 \mu \mathrm{g} / \mathrm{ml}$ induced significant reduction of phosphorylated Akt and enhancement of active RhoA signals in CGNs derived from postnatal 7-9 d LAR ${ }^{+/+}$ mice (Fig. 6A,C). Nevertheless, stimulation with CSPGs $(1.5 \mu \mathrm{g} /$ $\mathrm{ml}$ ) failed to induce significant changes of Akt-p and active RhoA 
A
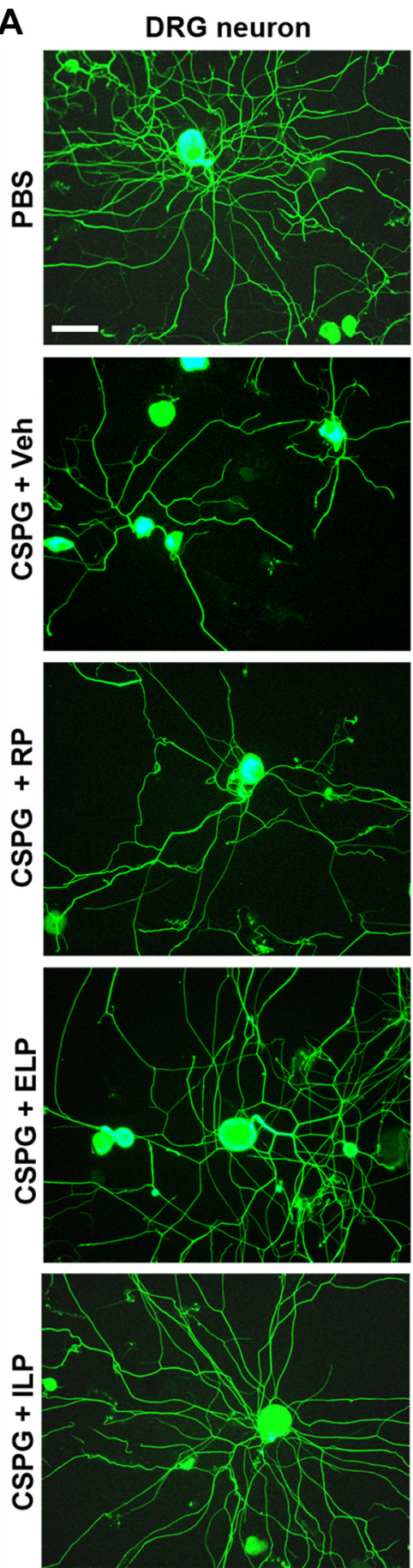

B

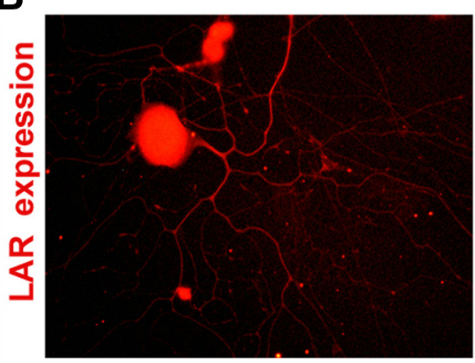

C
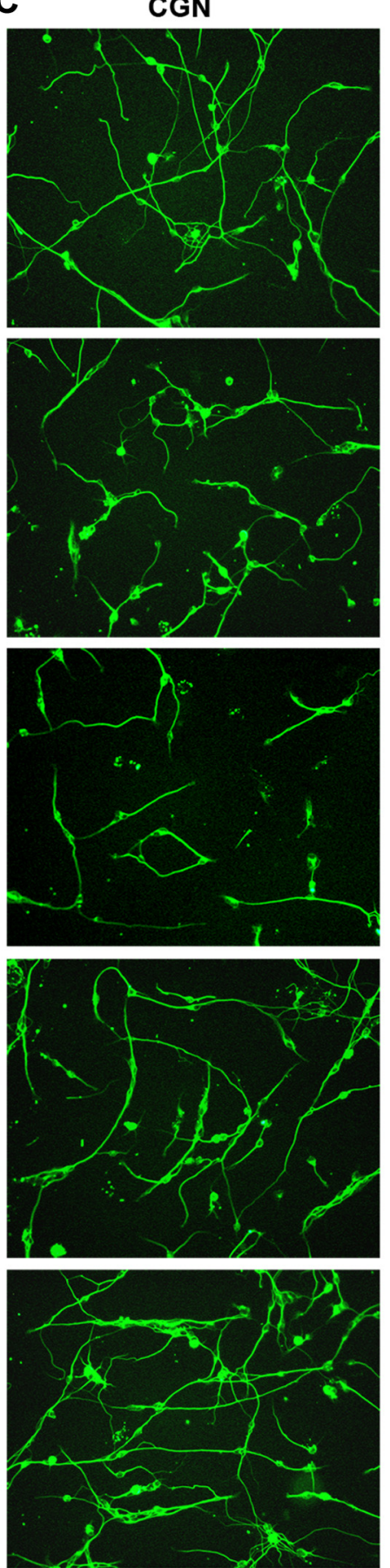

D

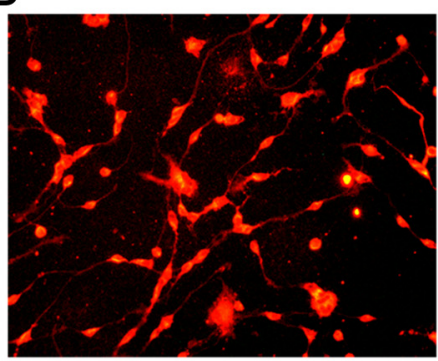

E

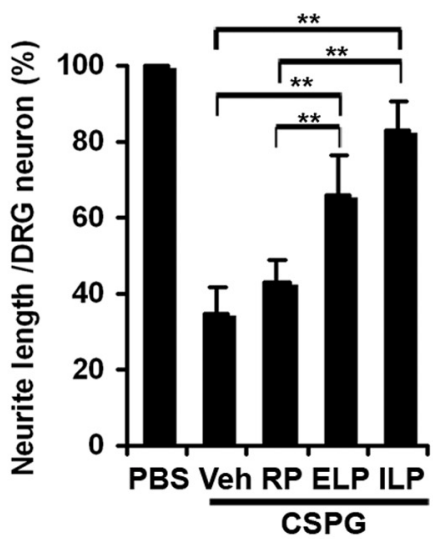

F
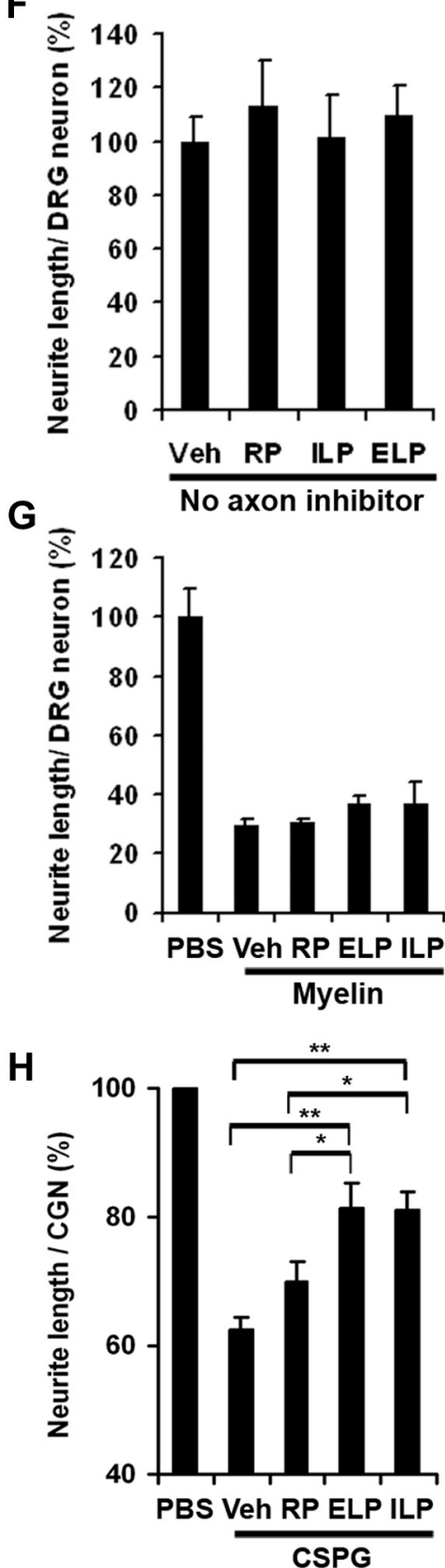

Figure 5. LAR blockade with peptides ELP and ILP significantly recovers neurite outgrowth in DRG neurons and CGNs cultured on CSPGS. A, C, DRG neurons derived from adult C57BL/6 mice and CGNs from postnatal 7-9 d C57BL/6 mice were cultured in the absence or presence of CSPGs (1.5 $\mu \mathrm{g} / \mathrm{ml})$ plus vehicle (Veh), RP, ELP, or ILP. Neurons were fixed and stained with an antibody against $\beta$ III-tubulin $24 \mathrm{~h}$ after growth. Both ELP and ILP significantly recovered neurite length of DRG neurons and CGNs on CSPGs. Scale bar, $50 \mu \mathrm{m} . \boldsymbol{B}, \boldsymbol{D}$, (Figure legend continues.) 

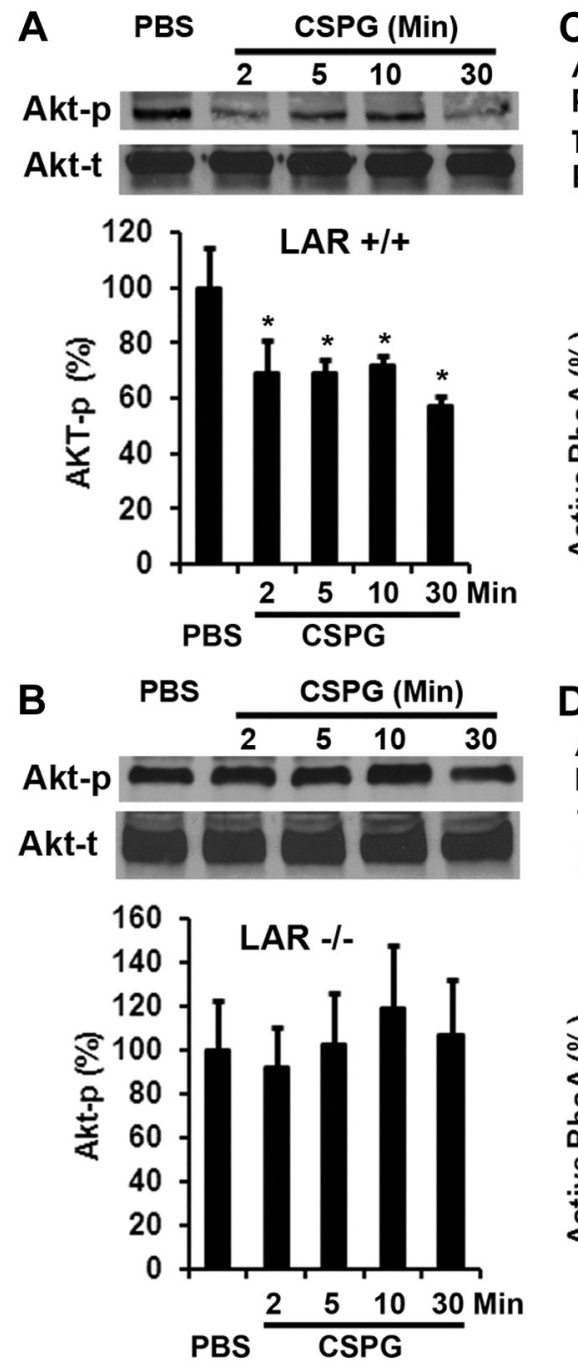
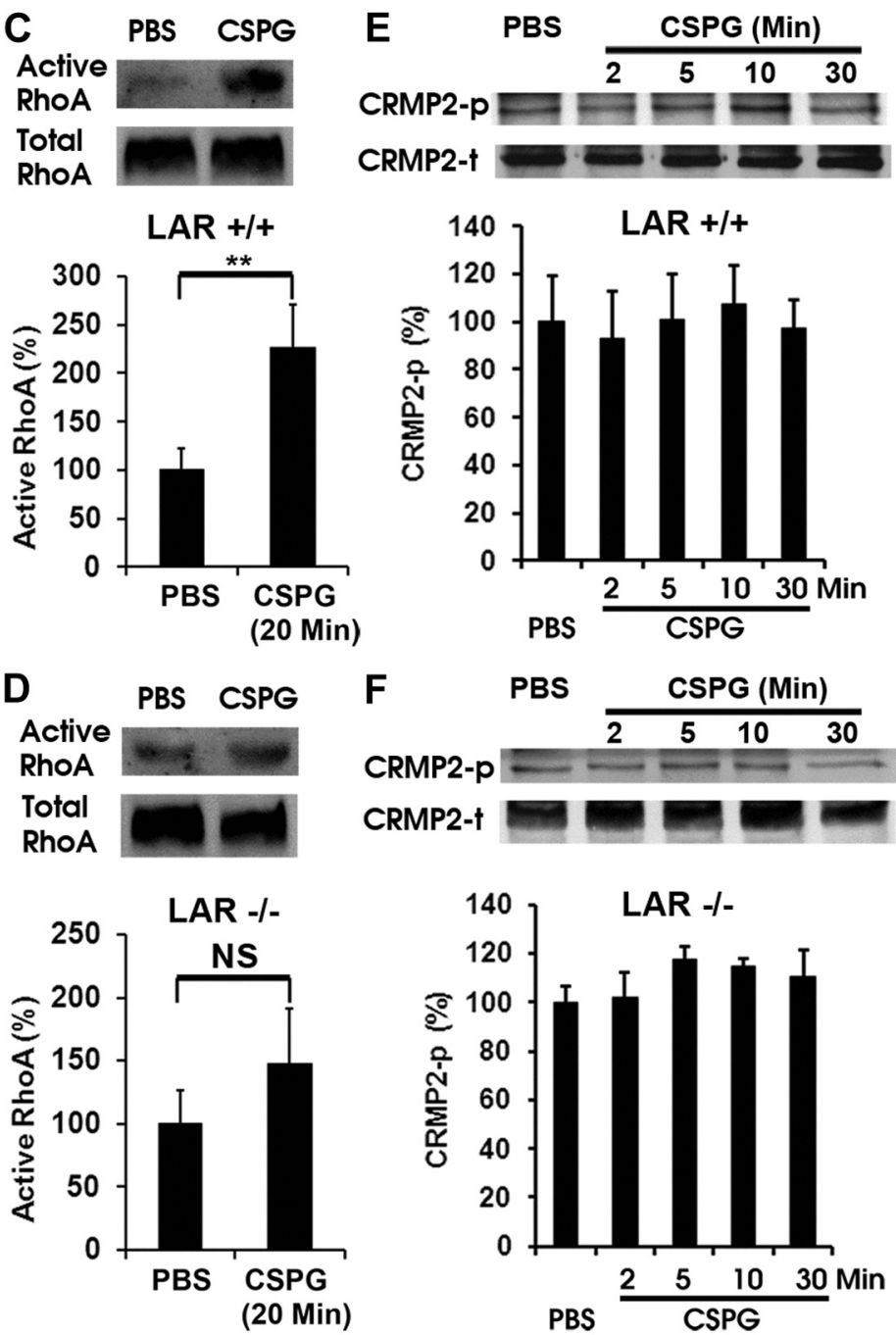

Figure 6. LAR deletion eliminates CSPG-induced Akt inactivation and RhoA activation in CGN cultures. $\boldsymbol{A}, \boldsymbol{B}$, Western blots indicate the levels of Akt- $\mathrm{p}$ (active form) in the supernatants of CGNs $24 \mathrm{~h}$ after cultures. Application of CSPG inhibitor $(1.5 \mu \mathrm{g} / \mathrm{ml})$ significantly reduced the levels of Akt-p 2-30 min after exposures in CGNs derived from LAR ${ }^{+/+}$mice $(\boldsymbol{A})$, although the total protein levels (Akt-t) are similar in the supernatants. However, application of CSPGs did not induce such a change of Akt-p in CGNs derived from LAR ${ }^{-1-}$ mice (B). The differences indicated are compared with PBS control. C, D, RhoA activity (top bands) was determined in cell supernatants of cultured CGNs $24 \mathrm{~h}$ after growth via RBD precipitation and Western blotting. Total RhoA levels (bottom bands) were determined from the same cell supernatants with blotting. Treatment with CSPGs (1.5 $\mu \mathrm{g} / \mathrm{ml})$ for 20 min significantly increases RhoA activation in neurons (C). Nevertheless, LAR deletion significantly eliminates RhoA activation induced by CSPG stimulation (D).E, F, Western blots indicate the levels of phosphorylated CRMP2 (CRMP2-p) (Thr514) in the supernatants of CGNs $24 \mathrm{~h}$ after

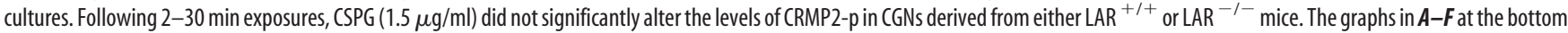
of the bands indicate the levels of signaling proteins in CGN supernatants quantified from four separate experiments. ${ }^{*} p<0.05$, ${ }^{* *} p<0.01$, Student's $t$ test. Error bars indicate SEM.

in cultured CGNs derived from $\mathrm{LAR}^{-1-}$ mice (Fig. $6 B, D$ ). These experiments suggest that CSPG-LAR interaction mediates axonal growth inhibition of neurons partly via inactivating Akt and activating RhoA signals.

CRMP-2 plays a critical role in regulating axonal formation and outgrowth during neuronal development via binding tubulin heterodimers and promoting microtubule assembly (Gu and

\footnotetext{
(Figure legend continued.) Immunostaining indicates LAR expression in the soma and neurites of DRG neurons and CGNs. The scale is the same as in $\boldsymbol{A}$. $\boldsymbol{E}-\boldsymbol{G}$, Neurite length per DRG neuron was quantified $24 \mathrm{~h}$ after cell plating. ELP and ILP treatments increased neurite length in the presence of CSPGs compared with cells treated with Veh or RP $(\boldsymbol{E})$, but did not significantly alter neurite length in the absence of axonal growth inhibitor $(\boldsymbol{F})$ or in the presence of CNS myelin (G). $\boldsymbol{H}$, Neurite length per CGN was quantified $24 \mathrm{~h}$ after cell plating. ELP and ILP treatments increased neurite length of CGNs in the presence of CSPGs compared with cells treated with Veh or $\mathrm{RP}$. In the graphs in $\boldsymbol{E}-\boldsymbol{H}$, the numbers indicate means \pm SEM from four to six coverslips $(8-10$ images/coverslip) in each group. ${ }^{*} p<0.05,{ }^{* *} p<0.01$, Student's $t$ test.
}

Ihara, 2000; Fukata et al., 2002; Yoshimura et al., 2005). Given that activation of GSK-3 $\beta$, the downstream signal of Akt, and RhoA contributes to growth cone collapse of axons by phosphorylating CRMP-2 at the threonine site and inactivating this protein (Arimura et al., 2005; Petratos et al., 2008), we examined whether altered Akt and RhoA activities following CSPG application would change the levels of phosphorylated CRMP-2 at Thr514 (CRMP2-p) in cultured neurons. We found that CSPG $(1.5 \mu \mathrm{g} /$ $\mathrm{ml}$ ) stimulation did not significantly affect the levels of CRMP2-p in cultured CGNs derived from either $\mathrm{LAR}^{+/+}$or $\mathrm{LAR}^{-/-}$mice (Fig. 6E,F). This finding suggests that phosphorylation of CRMP2 at Thr514 does not play a remarkable role for regulating CSPG-LAR interaction in neurons.

LAR-targeting peptides stimulate growth of descending fibers in mice with a thoracic dorsal transection injury

Given the inhibitory effect of LAR on axonal extension in vitro, suppression of this phosphatase via a pharmacological approach 
should enhance axonal growth following a CNS injury in vivo. We tested this hypothesis using a spinal cord injury model in rodents with a dorsal transection lesion at T7. This model is widely used for axonal regeneration and functional recovery studies (GrandPré et al., 2002; Fu et al., 2007) because it interrupts a group of defined pathways and provides tissue bridging for regenerating axons in the ventral spinal cord. Following SCI, the blood-brain barrier is absent for weeks to months around the lesion (Schnell et al., 1999), suggesting a route for penetration of peptides into the CNS after systemic administration. Conjugation of the TAT sequence to the intracellular LAR-targeting peptide can not only facilitate its penetration into cells (Schwarze et al., 1999; Futaki et al., 2001), but enhance its diffusion into the CNS following a systemic application (Rapoport and Lorberboum-Galski, 2009). Thus, LAR peptides should be able to efficiently penetrate into the lesioned spinal cord and bind cellular LAR following a systemic application. Several CSPGs are upregulated around 1-3 d after SCI and reach peak levels 1-2 weeks following the lesion (Jones et al., 2003). Based on the time course of CSPG upregulation, for in vivo axon regeneration experiments, we initiated treatments with vehicle DMSO, ELP (140 $\mu \mathrm{g} /$ mouse per day) or ILP ( $75 \mu \mathrm{g} /$ mouse per day) $2 \mathrm{~d}$ after injury via daily subcutaneous injections with syringes for 10 consecutive days. Because these peptides were dissolved in DMSO before dilution with PBS, we chose this solvent as the control in our in vivo experiments. Vehicles have been frequently used as controls for peptide or protein treatments in axon regeneration studies (GrandPré et al., 2002; Li and Strittmatter, 2003; Alilain et al., 2011; Zai et al., 2011) due to possible unforeseen toxic effects of using scrambled peptides in vivo. We applied a lower dose of ILP than ELP because of the higher in vitro potency of ILP for reversing CSPG inhibition. A few descending axonal pathways contribute to the extent of behavioral recovery after SCI, including descending raphespinal fiber tracts (Li et al., 2004). Thus, we characterized serotonergic fibers from transverse sections of SCI mice treated with vehicle or peptides via immunostaining with an antibody against 5-HT. Rostral to the lesion, a high density of 5-HT fibers were detected in transverse sections of the spinal cord, particularly in the ventral horns as well as the central and intermediolateral areas (Fig. $7 A, B)$. Five weeks after dorsal transection injury, the density of 5-HT-positive fibers was dramatically reduced in the caudal spinal cord (Fig. 7C,D) compared with sections rostral to the lesion (Li and Strittmatter, 2003). However, in samples from injured mice treated with ELP or ILP, the density of 5-HT fibers in the spinal cord 5-7 mm caudal to the lesion epicenter (at the upper lumbar levels) was significantly increased (Fig. 7E-H) compared with SCI controls although the density of 5-HT fibers 5-7 mm rostral to the lesion was similar among the three groups (data not shown). Moreover, longitudinal sections containing the lesion site displayed projection of a greater number of 5-HT-labeled axons into the reactive scar tissues around the lesion (data not shown) and the caudal spinal cord in ELP- and ILP-treated mice than in vehicle-treated controls (Fig. $7 J, K$ ). Although a similar number of 5-HT-positive axons was observed at $0-2.5 \mathrm{~mm}$ caudal to the lesion in ELP- and ILP-treated mice, ELP treatment induced a greater degree of axonal growth in the lumbar spinal cord more caudal to the injury site (5-7 $\mathrm{mm}$ to the lesion) than ILP (Fig. 7I), suggesting longer distance axonal growth in SCI mice treated with ELP.

We also evaluated whether treatments with ELP and ILP would promote functional recovery several weeks after SCI in mice. The standardized BMS was used to assess the outcome of these SCI rodents (Basso et al., 2006). The mice usually show no observable movement or slight-extensive ankle movement (BMS, 0-2) $2 \mathrm{~d}$ after the dorsal transection injury (Fig. $8 \mathrm{~A}$ ). A few weeks after the dorsal transection injury, control mice exhibit partial recovery probably due to short-range sprouting from spared fibers and reorganization of segmental circuitry including propriospinal reconnections (Courtine et al., 2008). The recovery reaches a stable level by 2-3 weeks after SCI. Generally, the control mice have frequent or consistent plantar stepping with limited or no coordination, and paws rotate when making the initial contact with the testing surface at initial contact and lift off. In contrast, the locomotor BMS in the ELP- or ILP-treated mice initiated $2 \mathrm{~d}$ after injury continues to increase $3-5$ weeks after SCI and the majority of them have consistent coordination plus parallel paw position at initial contact with the testing surface (Fig. $8 \mathrm{~A}$ ).

To further characterize locomotor recovery after SCI, we also performed a grid walking test in these mice. In this test, mice walked on a metal grid runway ( $10 \mathrm{~mm}$ between grids) and the incidence of their hindlimb slipping below the grid plane was evaluated from videotapes watched at a slow speed by an observer blind to experimental condition (Metz et al., 2000). Uninjured mice made very few errors on this test. Five weeks after injury, control mice made numerous errors by misplacing their hindpaws and falling into grid holes, but the mice treated with peptides, especially with ELP, made significantly fewer errors $(p<$ 0.01 for ELP, $p<0.05$ for ILP, Student's $t$ test) by correctly placing their hindpaws on the grid (Fig. $8 \mathrm{~B}$ ). Thus, these results demonstrate that treatments with LAR-targeting peptides significantly improve axonal growth and foster behavioral recovery in adult rodents with a dorsal transection SCI.

\section{Discussion}

Several strategies have been reported to repress CSPG inhibition (Grimpe and Silver, 2004; Laabs et al., 2007), but digestion of glycosaminoglycan chains with local application of bacterial chondroitinase $\mathrm{ABC}$ is the major in vivo approach to surmount growth inhibition of CSPGs after CNS injuries in rodents (Kwok et al., 2008; Alilain et al., 2011; Bradbury and Carter, 2011). Important disadvantages, however, may limit the use of ChABC as a therapeutic option for axonal injury patients, including incomplete removal of inhibitory components from CSPGs, short period of enzymatic activity at body temperature, inability to cross the blood-brain barrier due to large molecular size, and potential immune reactions after repeated injections. Thus, it is important to develop novel and more effective strategies for surmounting CSPG-mediated growth inhibitions. In this report, we have identified the transmembrane LAR phosphatase as an important mediator of CSPG effects in vitro. CSPGs bind LAR with high affinity and activate this phosphatase in vitro. LAR deletion in knock-out mice or blockade with peptides targeting sequences in either the extracellular or intracellular domains largely reverses growth suppression mediated by CSPG growth inhibitors. Our results suggest that LAR is a novel molecular target for overcoming growth restriction of the reactive glial scar tissues following CNS injuries.

The LAR subfamily of RPTPs has three vertebrate homologs, including LAR, RPTP $\delta$, and RPTP $\sigma$. The LAR ectodomain contains IgG-like and fibronectin type-III domains, and its transmembrane domain is followed by two cytosolic phosphatase domains D1 and D2 (Fig. 2A). D1 has protein tyrosine phosphatase (PTPase) activity by itself, and its conserved cysteine residue is essential for the PTPase activity (Tonks, 2006). The threedimensional structure of D2 is very similar to that of D1, but D2 

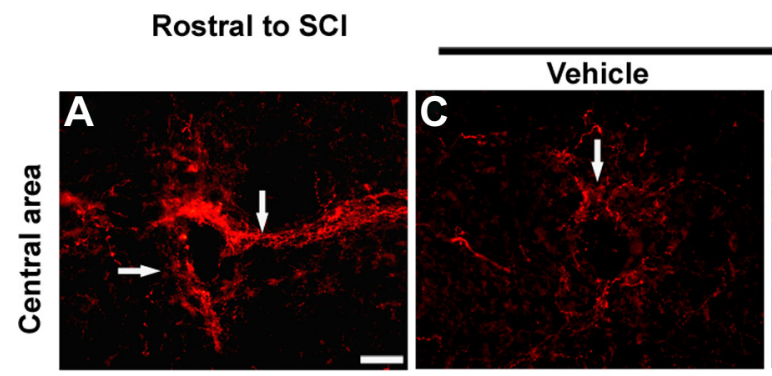

5-7 $\mathrm{mm}$ caudal to SCI
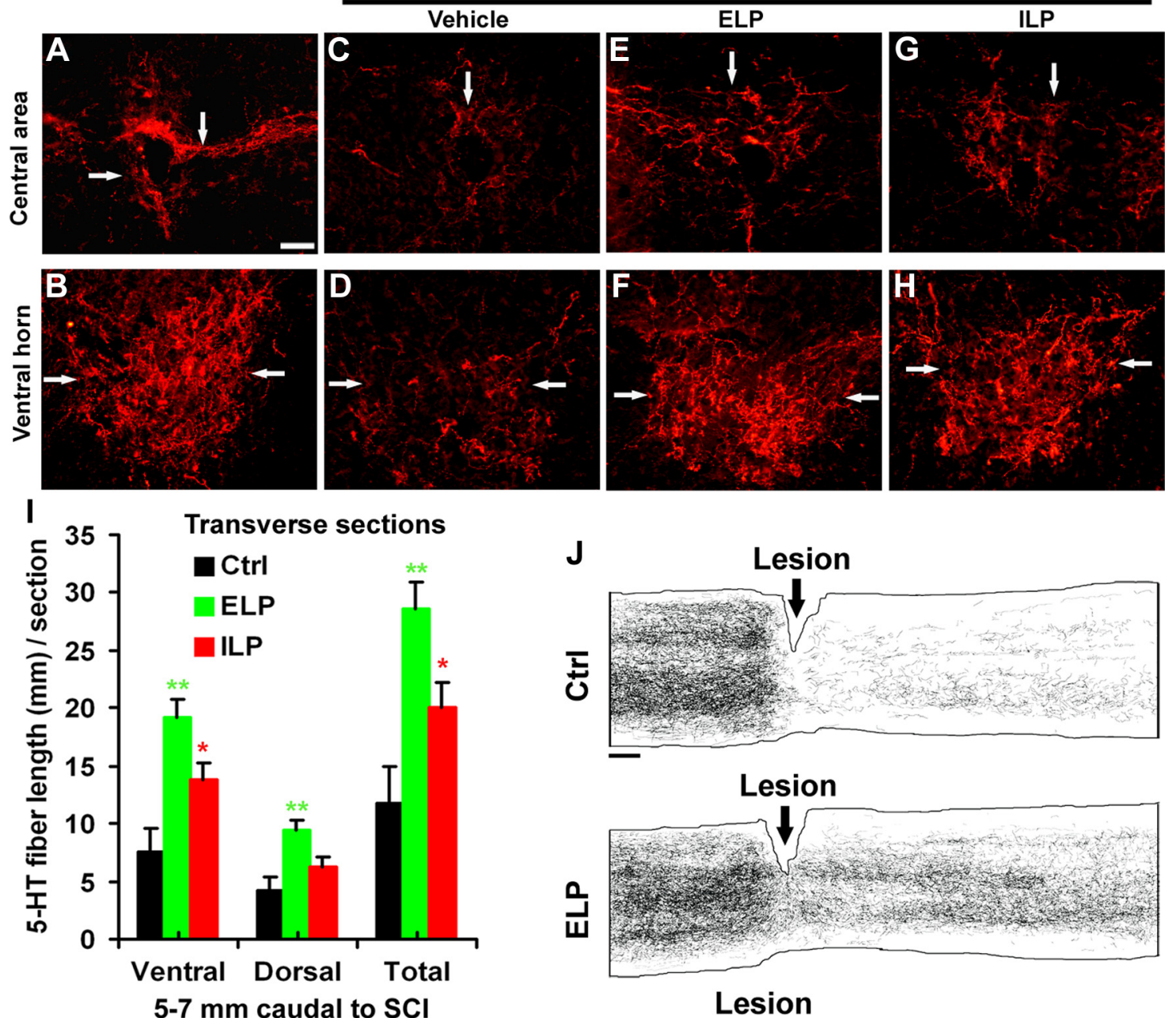

5-7 mm caudal to $\mathrm{SCI}$
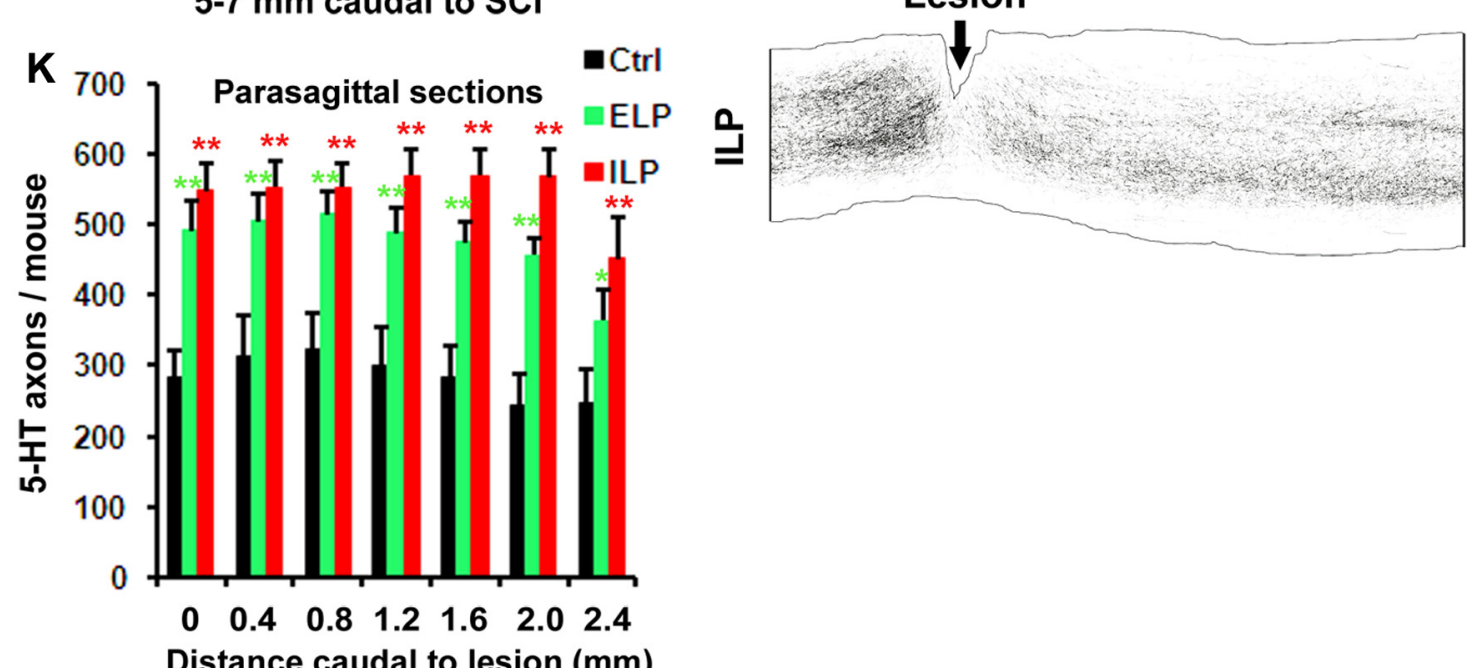

Figure 7. Systemic treatments with ELP and ILP enhance serotonergic fibers in the spinal cord caudal to a dorsal transection injury in mice. $\boldsymbol{A}, \boldsymbol{B}$, Transverse sections of the central and ventral spinal cord 5-7 mm rostral to SCI reveal high density of serotonergic fibers (arrows) in control SCI mice. $\mathbf{C}-\boldsymbol{H}$, Transverse sections of the spinal cord 5-7 mm caudal to the lesion at upper lumbar levels displayed the reduced 5-HT fibers 5 weeks after dorsal transection injury at T7 $(\boldsymbol{C}, \boldsymbol{D})$, but treatment with $\operatorname{ELP}(\boldsymbol{E}, \boldsymbol{F})$ or ILP $(\boldsymbol{G}, \boldsymbol{H})$ increased serotonergic fibers in both central and ventral part of the spinal cord compared with those from vehicle-treated mice $(\boldsymbol{C}, \boldsymbol{D})$. Scale bar, $50 \mu \mathrm{m}$. I, Serotonergic fiber length was measured from gray and white matter in dorsocentral areas and from gray matter in ventral horn of the spinal cord 5-7 mm caudal to the transection lesion. J, Camera lucida drawings of 5-HT fibers from all the parasagittal sections of each mouse are shown from control, ELP, and ILP animals. The animal from vehicle group shows a number of 5-HT axons in the distal spinal cord, indicating the spared serotonin axons following a dorsal over-transection injury at T7. In contrast, subcutaneous injections of ELP or ILP started $2 \mathrm{~d}$ after SCl result in a greater number of 5 -HT-positive axons in the distal spinal cord, particularly in the ventral areas. The dorsal is up in all these sections. Scale bar, $200 \mu \mathrm{m}$. $\boldsymbol{K}$, In a blind manner, serotonergic fiber number was counted from all parasagittal sections of the spinal cord $0-2.4 \mathrm{~mm}$ caudal to the lesion epicenter in each group. In graphs, means \pm SEM from six, five, and eight mice in control, ELP, and ILP groups are reported. ${ }^{*} p<0.05,{ }^{* *} p<0.01$, compared with vehicle-treated SCl controls, Student's $t$ test. 


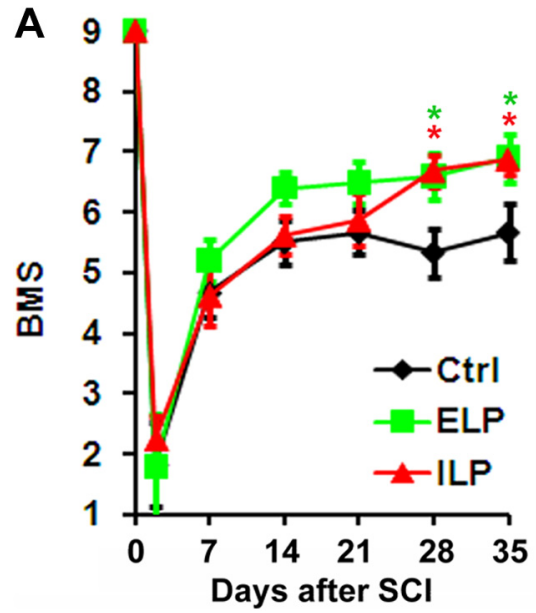

B

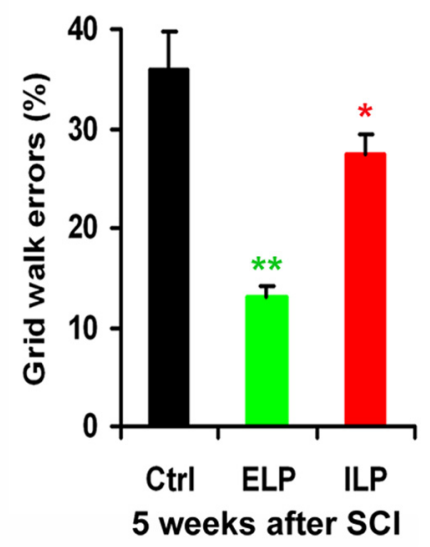

Figure 8. Systemic treatments with ELP and ILP improve locomotor recovery in SCI mice. $A$, The graph indicates the locomotor BMS in vehicle, ELP-treated (red color), or ILP-treated (green color) mice following dorsal transection SCI. B, Graph indicates grid walk errors in vehicle, ELP-treated (red color), or ILP-treated (green color) mice 5 weeks after dorsal transection SCI. In graphs, means \pm SEM from six, five, and eight mice in control, ELP, and ILP groups are reported. ${ }^{*} p<0.05,{ }^{* *} p<0.01$, compared with vehicle-treated SCI controls, repeated-measures ANOVA, or Student's $t$ test.

has no or very little intrinsic catalytic activity (Paul and Lombroso, 2003) and is mainly responsible for recognition of phosphorylated ligands and substrate specificity (Tsujikawa et al., 2001). Using dominant-negative LAR mutation and three different in vitro binding assays (Fig. $2 A, F, J, L$ ), we consistently demonstrate that the LAR D2 domain, the binding site of Liprin- $\alpha$, at least partially mediates the protein interactions between CSPGs and LAR. Similarly, LAR D2 has been shown to be important for recognition of LAR substrates including the insulin receptor as removal of the D2 domain altered the binding specificity of the LAR extracellular domain in vitro (Tsujikawa et al., 2001). The molecular mechanisms by which intracellular D2 regulates the binding of LAR to extracellular CSPG molecules are not clear. Previous studies suggest that RPTP dimerization is important for regulating functions of these phosphatases (Chagnon et al., 2004; den Hertog et al., 2008). Intracellular changes of RPTPs, such as phosphorylation or oxidation, may result in quaternary conformation alterations within RPTP dimers and modify their ligandbinding properties (den Hertog et al., 2008). Given the potential multiple functions of the intracellular LAR D2 domain (Chagnon et al., 2004), deletion of this domain might affect the binding capacity of extracellular ligands by altering the status of LAR dimerization or through other mechanisms. Intracellularly, the interaction of LAR with catenin and other proteins appears to regulate actin cytoskeleton dynamics and neuronal extension (Dunah et al., 2005; Haapasalo et al., 2007). Moreover, our finding suggests that the GAG chains of CSPGs are critical for their binding to LAR since CSPG digestion with ChABC largely removes the binding affinity (Fig. $2 H$ ).

LAR is highly expressed by multiple neuronal populations (Fig. 1) and has been localized to neurites and neuronal growth cones (Fig. 5) (J. S. Zhang et al., 1998). LAR is conserved during evolution and predominantly functions in the nervous system by regulating cell adhesion, synaptic formation and maintenance, and learning and memory during development and in the adult (Paul and Lombroso, 2003). The extracellular domains of LAR have been reported to bind a few axon growth-regulating molecules, including laminin-nidogen complex in HeLa cells and HSPGs in Drosophila (O'Grady et al., 1998; Fox and Zinn, 2005; Johnson et al., 2006), but the physiological ligand(s) for LAR in mammals remains unclear. Our study demonstrates that CSPG molecules bind LAR with high affinity and interact with this phosphatase, suggesting that CSPGs may function as the ligands for LAR in mammals. In fact, CSPGs have been shown to have similar regulatory functions to LAR in neurons, including those involving cell adhesion and differentiation during development as well as controlling synaptic and structural plasticity in adult CNS (Carulli et al., 2005). Furthermore, a recent study indicates that a conserved, positively charged region on the surface of the first IgG-like domain of $\operatorname{RPTP} \sigma$, also a member in the LAR subfamily, interacts with chondroitin sulfate, the negatively charged region of CSPGs (Shen et al., 2009). Thus, our study, together with the most recent report (Shen et al., 2009), suggests that CSPGs are the ligands for some RPTP members, including LAR and RPTP $\sigma$.

Our results support the crucial role of LAR in mediating CSPG inhibition of axon outgrowth. CSPG stimulation increases LAR phosphatase activity. LAR deletion in transgenic mice or blockade with peptides derived from either the ectodomain or intracellular wedge-shaped helix-loop-helix of LAR promotes significant neurite and axon outgrowth in mature DRG neurons or in postnatal cerebellar neurons cultured on CSPG substrates. LAR antagonistic peptides also effectively reverse growth cone collapse of embryonic DRG neurons induced by CSPGs (data not shown). In contrast, LAR-targeting peptides did not surmount growth repression induced by other types of axonal growth inhibitors such as CNS myelin (Fig. 5G). Also, transgenic LAR deletion eliminates CSPG-induced intracellular Akt inactivation and RhoA activation in neurons. Moreover, using a SCI model, we demonstrate that systemic application of LARtargeting peptides enhances axonal growth of the descending raphespinal tracts as well as locomotor functional recovery in adult rodents. Inhibition of CSPG signals is most likely to be the basis for the increased axonal growth and improved behavioral recovery of SCI rodents in this study, although we cannot exclude the possibility that LAR inhibition benefits recovery through other mechanisms because LAR ligands in the CNS are largely unknown. Previously, the laboratory of F. M. Longo demonstrated that LAR-targeting peptides increased neurite elongation in immature cells including PC12 cells and mouse E16-E17 hippocampal neurons (Yang et al., 2003, 2005; Xie et al., 2006). The positive effect of the LAR peptides detected in previous studies might represent LAR blockade overcoming repression of CSPGs expressed on neuronal/glial membrane (Lander et al., 1997) and/or interfering with other functions of LAR (Xie et al., 2006).

Following SCI, the extent of locomotor function recovery generally depends on reorganization of segmental circuitry and restoration of supraspinal input. Segmental mechanisms appear to play a major role in the locomotor recovery of control SCI mice treated with vehicle due to lack of obvious axonal regeneration. However, in addition to enhanced plasticity at segmental levels, restoration of supraspinal input to the caudal spinal cord appears to participate in the functional improvement in the animals treated with LAR-targeting peptides. Treatment with ELP or ILP 
induces axonal growth in the spinal cord below the lesion and significantly increases the number of descending raphespinal tract fibers. Consistently, serotonergic neurons express high levels of LAR protein (data not shown). Given the widespread neuronal distribution of LAR in the CNS, it is very likely that additional fiber systems are responsive to the LAR-targeting peptides and could contribute to the improved performance of SCI mice.

LAR blockade with transgenic or pharmacological approaches partially recovers neurite growth of neurons on CSPG inhibitors (Figs. $4 A, B, 5 E, H$ ). The remaining suppressing effects of CSPGs following LAR inhibition are likely to be mediated by additional receptors and receptor-independent mechanisms. By using RPTP $\sigma$ mutant mice, the groups of J. G. Flanagan (Harvard Medical School, Boston, MA) and J. Silver convincingly demonstrate that neuronal RPTP $\sigma$ is a receptor for CSPG molecules and partly mediates inhibitory effects of reactive scar tissues. Following a dorsal transection SCI, sensory axons in RPTP $\sigma^{-1-}$ mice extended into the glial scar tissues but did not regenerate robustly beyond the lesion center of the spinal cord (Shen et al., 2009). Consistently, another group reported a limited degree of corticospinal axonal regeneration in RPTP $\sigma^{-1-}$ mice after SCI (Fry et al., 2010). Thus, our study, together with these reports, suggests that axon growth inhibition of the CSPG-rich scar tissues is mainly or completely mediated by neuronal transmembrane LAR and $\operatorname{RPTP} \sigma$, two members in the LAR subfamily, although we cannot exclude other possible CSPG receptor proteins and receptor-independent mechanisms. Thus, it will be very interesting to determine whether inhibition of both LAR and RPTP $\sigma$ via transgenic or pharmacological approaches will more completely surmount CSPG suppression and achieve more extensive axonal regeneration in vivo.

The current identification of a novel receptor for mediating CSPG actions should greatly advance our understanding of axon growth inhibition mediated by glial scar tissues following CNS injuries. More importantly, our study should facilitate development of an effective therapy for a number of neurological disorders that involve inhibition of axonal outgrowth including spinal cord injury, brain trauma, and white matter stroke. Particularly, subcutaneous injections of the LAR antagonistic peptides initiated $2 \mathrm{~d}$ after axonal lesions might provide a basis for achieving effective axonal regeneration and locomotor recovery in adult mammals with CNS axonal injuries given the obvious advantages of peptides over the bacterial enzyme $\mathrm{ChABC}$ and the wide applications of Food and Drug Administration-approved peptide drugs in humans.

\section{References}

Alilain WJ, Horn KP, Hu H, Dick TE, Silver J (2011) Functional regeneration of respiratory pathways after spinal cord injury. Nature 475:196-200.

Arimura N, Ménager C, Kawano Y, Yoshimura T, Kawabata S, Hattori A, Fukata Y, Amano M, Goshima Y, Inagaki M, Morone N, Usukura J, Kaibuchi K (2005) Phosphorylation by Rho kinase regulates CRMP-2 activity in growth cones. Mol Cell Biol 25:9973-9984.

Basso DM, Fisher LC, Anderson AJ, Jakeman LB, McTigue DM, Popovich PG (2006) Basso Mouse Scale for locomotion detects differences in recovery after spinal cord injury in five common mouse strains. J Neurotrauma 23:635-659.

Bradbury EJ, Carter LM (2011) Manipulating the glial scar: chondroitinase $\mathrm{ABC}$ as a therapy for spinal cord injury. Brain Res Bull 84:306-316.

Bradbury EJ, Moon LD, Popat RJ, King VR, Bennett GS, Patel PN, Fawcett JW, McMahon SB (2002) Chondroitinase ABC promotes functional recovery after spinal cord injury. Nature 416:636-640.

Cafferty WB, Yang SH, Duffy PJ, Li S, Strittmatter SM (2007) Functional axonal regeneration through astrocytic scar genetically modified to digest chondroitin sulfate proteoglycans. J Neurosci 27:2176-2185.

Carulli D, Laabs T, Geller HM, Fawcett JW (2005) Chondroitin sulfate proteoglycans in neural development and regeneration. Curr Opin Neurobiol 15:116-120.

Chadborn NH, Ahmed AI, Holt MR, Prinjha R, Dunn GA, Jones GE, Eickholt BJ (2006) PTEN couples Sema3A signalling to growth cone collapse. J Cell Sci 119:951-957.

Chagnon MJ, Uetani N, Tremblay ML (2004) Functional significance of the LAR receptor protein tyrosine phosphatase family in development and diseases. Biochem Cell Biol 82:664-675.

Courtine G, Song B, Roy RR, Zhong H, Herrmann JE, Ao Y, Qi J, Edgerton VR, Sofroniew MV (2008) Recovery of supraspinal control of stepping via indirect propriospinal relay connections after spinal cord injury. Nat Med 14:69-74.

den Hertog J, Ostman A, Böhmer FD (2008) Protein tyrosine phosphatases: regulatory mechanisms. FEBS J 275:831-847.

Dill J, Wang H, Zhou F, Li S (2008) Inactivation of glycogen synthase kinase- 3 promotes axonal growth and recovery in the CNS. J Neurosci 28:8914-8928.

Dill J, Patel AR, Yang XL, Bachoo R, Powell CM, Li S (2010) A molecular mechanism for ibuprofen-mediated RhoA inhibition in neurons. J Neurosci 30:963-972.

Dunah AW, Hueske E, Wyszynski M, Hoogenraad CC, Jaworski J, Pak DT, Simonetta A, Liu G, Sheng M (2005) LAR receptor protein tyrosine phosphatases in the development and maintenance of excitatory synapses. Nat Neurosci 8:458-467.

Fouad K, Schnell L, Bunge MB, Schwab ME, Liebscher T, Pearse DD (2005) Combining Schwann cell bridges and olfactory-ensheathing glia grafts with chondroitinase promotes locomotor recovery after complete transection of the spinal cord. J Neurosci 25:1169-1178.

Fox AN, Zinn K (2005) The heparan sulfate proteoglycan syndecan is an in vivo ligand for the Drosophila LAR receptor tyrosine phosphatase. Curr Biol 15:1701-1711.

Fry EJ, Chagnon MJ, López-Vales R, Tremblay ML, David S (2010) Corticospinal tract regeneration after spinal cord injury in receptor protein tyrosine phosphatase sigma deficient mice. Glia 58:423-433.

Fu Q, Hue J, Li S (2007) Nonsteroidal anti-inflammatory drugs promote axon regeneration via RhoA inhibition. J Neurosci 27:4154-4164.

Fukata Y, Itoh TJ, Kimura T, Ménager C, Nishimura T, Shiromizu T, Watanabe H, Inagaki N, Iwamatsu A, Hotani H, Kaibuchi K (2002) CRMP-2 binds to tubulin heterodimers to promote microtubule assembly. Nat Cell Biol 4:583-591.

Futaki S, Suzuki T, Ohashi W, Yagami T, Tanaka S, Ueda K, Sugiura Y (2001) Arginine-rich peptides. An abundant source of membrane-permeable peptides having potential as carriers for intracellular protein delivery. J Biol Chem 276:5836-5840.

García-Alías G, Lin R, Akrimi SF, Story D, Bradbury EJ, Fawcett JW (2008) Therapeutic time window for the application of chondroitinase $\mathrm{ABC}$ after spinal cord injury. Exp Neurol 210:331-338.

Gilbert RJ, McKeon RJ, Darr A, Calabro A, Hascall VC, Bellamkonda RV (2005) CS-4,6 is differentially upregulated in glial scar and is a potent inhibitor of neurite extension. Mol Cell Neurosci 29:545-558.

GrandPré T, Li S, Strittmatter SM (2002) Nogo-66 receptor antagonist peptide promotes axonal regeneration. Nature 417:547-551.

Grimpe B, Silver J (2004) A novel DNA enzyme reduces glycosaminoglycan chains in the glial scar and allows microtransplanted dorsal root ganglia axons to regenerate beyond lesions in the spinal cord. J Neurosci 24:1393-1397.

$\mathrm{Gu}$ Y, Ihara Y (2000) Evidence that collapsin response mediator protein-2 is involved in the dynamics of microtubules. J Biol Chem 275:17917-17920

Haapasalo A, Kim DY, Carey BW, Turunen MK, Pettingell WH, Kovacs DM (2007) Presenilin/gamma-secretase-mediated cleavage regulates association of leukocyte-common antigen-related (LAR) receptor tyrosine phosphatase with $\beta$-catenin. J Biol Chem 282:9063-9072.

Houle JD, Tom VJ, Mayes D, Wagoner G, Phillips N, Silver J (2006) Combining an autologous peripheral nervous system "bridge" and matrix modification by chondroitinase allows robust, functional regeneration beyond a hemisection lesion of the adult rat spinal cord. J Neurosci 26:7405-7415.

Irie F, Okuno M, Matsumoto K, Pasquale EB, Yamaguchi Y (2008) Heparan 
sulfate regulates ephrin-A3/EphA receptor signaling. Proc Natl Acad Sci U S A 105:12307-12312.

Jefferson SC, Tester NJ, Howland DR (2011) Chondroitinase ABC promotes recovery of adaptive limb movements and enhances axonal growth caudal to a spinal hemisection. J Neurosci 31:5710-5720.

Johnson KG, Tenney AP, Ghose A, Duckworth AM, Higashi ME, Parfitt K, Marcu O, Heslip TR, Marsh JL, Schwarz TL, Flanagan JG, Van Vactor D (2006) The HSPGs Syndecan and Dallylike bind the receptor phosphatase LAR and exert distinct effects on synaptic development. Neuron 49:517-531.

Jones LL, Margolis RU, Tuszynski MH (2003) The chondroitin sulfate proteoglycans neurocan, brevican, phosphacan, and versican are differentially regulated following spinal cord injury. Exp Neurol 182:399-411.

Kantor DB, Chivatakarn O, Peer KL, Oster SF, Inatani M, Hansen MJ, Flanagan JG, Yamaguchi Y, Sretavan DW, Giger RJ, Kolodkin AL (2004) Semaphorin $5 \mathrm{~A}$ is a bifunctional axon guidance cue regulated by heparan and chondroitin sulfate proteoglycans. Neuron 44:961-975.

Kim BG, Dai HN, Lynskey JV, McAtee M, Bregman BS (2006) Degradation of chondroitin sulfate proteoglycans potentiates transplant-mediated axonal remodeling and functional recovery after spinal cord injury in adult rats. J Comp Neurol 497:182-198.

Klein R (2004) Eph/ephrin signaling in morphogenesis, neural development and plasticity. Curr Opin Cell Biol 16:580-589.

Kolkman MJ, Streijger F, Linkels M, Bloemen M, Heeren DJ, Hendriks WJ, Van der Zee CE (2004) Mice lacking leukocyte common antigen-related (LAR) protein tyrosine phosphatase domains demonstrate spatial learning impairment in the two-trial water maze and hyperactivity in multiple behavioural tests. Behav Brain Res 154:171-182.

Kwok JC, Afshari F, García-Alías G, Fawcett JW (2008) Proteoglycans in the central nervous system: plasticity, regeneration and their stimulation with chondroitinase ABC. Restor Neurol Neurosci 26:131-145.

Laabs TL, Wang H, Katagiri Y, McCann T, Fawcett JW, Geller HM (2007) Inhibiting glycosaminoglycan chain polymerization decreases the inhibitory activity of astrocyte-derived chondroitin sulfate proteoglycans. J Neurosci 27:14494-14501.

Lander C, Kind P, Maleski M, Hockfield S (1997) A family of activitydependent neuronal cell-surface chondroitin sulfate proteoglycans in cat visual cortex. J Neurosci 17:1928-1939.

Li S, Strittmatter SM (2003) Delayed systemic Nogo-66 receptor antagonist promotes recovery from spinal cord injury. J Neurosci 23:4219-4227.

Li S, Liu BP, Budel S, Li M, Ji B, Walus L, Li W, Jirik A, Rabacchi S, Choi E, Worley D, Sah DW, Pepinsky B, Lee D, Relton J, Strittmatter SM (2004) Blockade of Nogo-66, myelin-associated glycoprotein, and oligodendrocyte myelin glycoprotein by soluble Nogo-66 receptor promotes axonal sprouting and recovery after spinal injury. J Neurosci 24:10511-10520.

Liu BP, Cafferty WB, Budel SO, Strittmatter SM (2006) Extracellular regulators of axonal growth in the adult central nervous system. Philos Trans R Soc Lond B Biol Sci 361:1593-1610.

Loup F, Picard F, Yonekawa Y, Wieser HG, Fritschy JM (2009) Selective changes in $\mathrm{GABA}_{\mathrm{A}}$ receptor subtypes in white matter neurons of patients with focal epilepsy. Brain 132:2449-2463.

McKeon RJ, Schreiber RC, Rudge JS, Silver J (1991) Reduction of neurite outgrowth in a model of glial scarring following CNS injury is correlated with the expression of inhibitory molecules on reactive astrocytes. J Neurosci 11:3398-3411.

Metz GA, Merkler D, Dietz V, Schwab ME, Fouad K (2000) Efficient testing of motor function in spinal cord injured rats. Brain Res 883:165-177.

Monnier PP, Sierra A, Schwab JM, Henke-Fahle S, Mueller BK (2003) The Rho/ROCK pathway mediates neurite growth-inhibitory activity associated with the chondroitin sulfate proteoglycans of the CNS glial scar. Mol Cell Neurosci 22:319-330.

Moon LD, Asher RA, Rhodes KE, Fawcett JW (2001) Regeneration of CNS axons back to their target following treatment of adult rat brain with chondroitinase ABC. Nat Neurosci 4:465-466.

O'Grady P, Thai TC, Saito H (1998) The laminin-nidogen complex is a ligand for a specific splice isoform of the transmembrane protein tyrosine phosphatase LAR. J Cell Biol 141:1675-1684.

Paul S, Lombroso PJ (2003) Receptor and nonreceptor protein tyrosine phosphatases in the nervous system. Cell Mol Life Sci 60:2465-2482.

Petratos S, Li QX, George AJ, Hou X, Kerr ML, Unabia SE, Hatzinisiriou I,
Maksel D, Aguilar MI, Small DH (2008) The beta-amyloid protein of Alzheimer's disease increases neuronal CRMP-2 phosphorylation by a Rho-GTP mechanism. Brain 131:90-108.

Qin C, Huang B, Wygant JN, McIntyre BW, McDonald CH, Cook RG, Butler WT (2006) A chondroitin sulfate chain attached to the bone dentin matrix protein $1 \mathrm{NH} 2$-terminal fragment. J Biol Chem 281:8034-8040.

Rapoport M, Lorberboum-Galski H (2009) TAT-based drug delivery system-new directions in protein delivery for new hopes? Expert Opin Drug Deliv 6:453-463.

Sandy JD, Westling J, Kenagy RD, Iruela-Arispe ML, Verscharen C, Rodriguez-Mazaneque JC, Zimmermann DR, Lemire JM, Fischer JW, Wight TN, Clowes AW (2001) Versican V1 proteolysis in human aorta in vivo occurs at the Glu441-Ala442 bond, a site that is cleaved by recombinant ADAMTS-1 and ADAMTS-4. J Biol Chem 276:13372-13378.

Schnell L, Fearn S, Klassen H, Schwab ME, Perry VH (1999) Acute inflammatory responses to mechanical lesions in the CNS: differences between brain and spinal cord. Eur J Neurosci 11:3648-3658.

Schwarze SR, Ho A, Vocero-Akbani A, Dowdy SF (1999) In vivo protein transduction: delivery of a biologically active protein into the mouse. Science 285:1569-1572.

Serra-Pagès C, Medley QG, Tang M, Hart A, Streuli M (1998) Liprins, a family of LAR transmembrane protein-tyrosine phosphatase-interacting proteins. J Biol Chem 273:15611-15620.

Shen Y, Tenney AP, Busch SA, Horn KP, Cuascut FX, Liu K, He Z, Silver J, Flanagan JG (2009) PTPsigma is a receptor for chondroitin sulfate proteoglycan, an inhibitor of neural regeneration. Science 326:592-596.

Sherman LS, Back SA (2008) A "GAG" reflex prevents repair of the damaged CNS. Trends Neurosci 31:44-52.

Silver J, Miller JH (2004) Regeneration beyond the glial scar. Nat Rev Neurosci 5:146-156.

Snow DM, Lemmon V, Carrino DA, Caplan AI, Silver J (1990) Sulfated proteoglycans in astroglial barriers inhibit neurite outgrowth in vitro. Exp Neurol 109:111-130.

Tester NJ, Howland DR (2008) Chondroitinase ABC improves basic and skilled locomotion in spinal cord injured cats. Exp Neurol 209:483-496.

Tom VJ, Sandrow-Feinberg HR, Miller K, Santi L, Connors T, Lemay MA, Houlé JD (2009) Combining peripheral nerve grafts and chondroitinase promotes functional axonal regeneration in the chronically injured spinal cord. J Neurosci 29:14881-14890.

Tonks NK (2006) Protein tyrosine phosphatases: from genes, to function, to disease. Nat Rev Mol Cell Biol 7:833-846.

Tsujikawa K, Kawakami N, Uchino Y, Ichijo T, Furukawa T, Saito H, Yamamoto H (2001) Distinct functions of the two protein tyrosine phosphatase domains of LAR (leukocyte common antigen-related) on tyrosine dephosphorylation of insulin receptor. Mol Endocrinol 15:271-280.

Ughrin YM, Chen ZJ, Levine JM (2003) Multiple regions of the NG2 proteoglycan inhibit neurite growth and induce growth cone collapse. J Neurosci 23:175-186.

Van Vactor D, Wall DP, Johnson KG (2006) Heparan sulfate proteoglycans and the emergence of neuronal connectivity. Curr Opin Neurobiol $16: 40-51$.

Wang H, Katagiri Y, McCann TE, Unsworth E, Goldsmith P, Yu ZX, Tan F, Santiago L, Mills EM, Wang Y, Symes AJ, Geller HM (2008) Chondroitin4-sulfation negatively regulates axonal guidance and growth. J Cell Sci 121:3083-3091.

Xie Y, Yeo TT, Zhang C, Yang T, Tisi MA, Massa SM, Longo FM (2001) The leukocyte common antigen-related protein tyrosine phosphatase receptor regulates regenerative neurite outgrowth in vivo. J Neurosci 21:5130-5138.

Xie Y, Massa SM, Ensslen-Craig SE, Major DL, Yang T, Tisi MA, Derevyanny VD, Runge WO, Mehta BP, Moore LA, Brady-Kalnay SM, Longo FM (2006) Protein-tyrosine phosphatase (PTP) wedge domain peptides: a novel approach for inhibition of PTP function and augmentation of protein-tyrosine kinase function. J Biol Chem 281:16482-16492.

Yang T, Bernabeu R, Xie Y, Zhang JS, Massa SM, Rempel HC, Longo FM (2003) Leukocyte antigen-related protein tyrosine phosphatase receptor: a small ectodomain isoform functions as a homophilic ligand and promotes neurite outgrowth. J Neurosci 23:3353-3363.

Yang T, Yin W, Derevyanny VD, Moore LA, Longo FM (2005) Identification of an ectodomain within the LAR protein tyrosine phosphatase re- 
ceptor that binds homophilically and activates signalling pathways promoting neurite outgrowth. Eur J Neurosci 22:2159-2170.

Yeo TT, Yang T, Massa SM, Zhang JS, Honkaniemi J, Butcher LL, Longo FM (1997) Deficient LAR expression decreases basal forebrain cholinergic neuronal size and hippocampal cholinergic innervation. J Neurosci Res 47:348-360.

Yoshimura T, Kawano Y, Arimura N, Kawabata S, Kikuchi A, Kaibuchi K (2005) GSK-3beta regulates phosphorylation of CRMP-2 and neuronal polarity. Cell 120:137-149.

Zai L, Ferrari C, Dice C, Subbaiah S, Havton LA, Coppola G, Geschwind D, Irwin N, Huebner E, Strittmatter SM, Benowitz LI (2011) Inosine augments the effects of a Nogo receptor blocker and of environmental en- richment to restore skilled forelimb use after stroke. J Neurosci 31: 5977-5988.

Zhang JS, Honkaniemi J, Yang T, Yeo TT, Longo FM (1998) LAR tyrosine phosphatase receptor: a developmental isoform is present in neurites and growth cones and its expression is regional- and cell-specific. Mol Cell Neurosci 10:271-286.

Zhang Y, Cao L, Yang BL, Yang BB (1998) The G3 domain of versican enhances cell proliferation via epidermial growth factor-like motifs. J Biol Chem 273:21342-21351.

Zhou FQ, Zhou J, Dedhar S, Wu YH, Snider WD (2004) NGF-induced axon growth is mediated by localized inactivation of GSK-3beta and functions of the microtubule plus end binding protein APC. Neuron 42:897-912. 